\title{
Investigating Economic Growth, Trade Issues and Future Energy Strategies for Central Asian Countries
}

\author{
Olimjon Djumabaev, Tatsuo Oyama \\ National Graduate Institute for Policy Studies 7-22-1 Roppongi, Minato-ku, Tokyo, Japan \\ Email: doc14101@grips.ac.jp, oyamat@grips.ac.jp
}

How to cite this paper: Djumabaev, O. and Oyama, T. (2018) Investigating Economic Growth, Trade Issues and Future Energy Strategies for Central Asian Countries. American Journal of Operations Research, 8, 486-519.

https://doi.org/10.4236/ajor.2018.86028

Received: September 11, 2018

Accepted: November 27, 2018

Published: November 30, 2018

Copyright (c) 2018 by authors and Scientific Research Publishing Inc. This work is licensed under the Creative Commons Attribution International License (CC BY 4.0).

http://creativecommons.org/licenses/by/4.0/

\begin{abstract}
We examine the economic growth, energy development policies and strategies for the CAC from various perspectives. We apply statistical data analysis techniques and mathematical modelling methodologies focusing upon regression model analysis in order to deal with the economic and energy related data during the period 1990-2014, and to investigate the relationship among economic growth, energy production, and the trade of energy resources in order to find future desirable policies and strategies for the CAC. Findings show that energy production growth would bring statistically significant positive impact on GDP growth in fossil-fuel rich Kazakhstan, Uzbekistan, and Turkmenistan while we also find negative impact of GDP growth on the trade balance of the CAC except for Turkmenistan. Another finding follows that the foreign direct investment has a significant influence on the trade balance in the cases of Uzbekistan and Turkmenistan, which institute import substitution policies right from their initial years of independence. Based on these quantitative investigations on economy, energy, and trades we propose future energy strategies for the CAC, stressing the importance of diversification of economies.
\end{abstract}

\section{Keywords}

Central Asian Countries, Energy Development Policy, Statistical Data

Analysis, Mathematical Model, Natural Resources Trade, Regression Model

\section{Introduction}

The CAC are located in the heart of the Eurasian continent and consist of five landlocked countries: Kazakhstan (KAZ), Uzbekistan (UZB), Turkmenistan 
(TUR), Kyrgyz Republic (KYR) and Tajikistan (TAJ), which have borders with Europe, Russia, China, Pakistan, Afghanistan, and Middle East from the north to the east and south, respectively. The entire territory of the region spreads over an area of about 4 million square kilometers, of which almost $69 \%$ of the region belongs to KAZ, while the other four countries share the remaining $31 \%$ with the smallest share occupied by KYR and TAJ. Since the region is located at the heart of Eurasia and connects the four main parts of this continent, Europe, Russia, Asia, and the Middle East, it has been of central geopolitical interest to major powers over many centuries. The CAC are one of the most important natural resource rich regions in the world, notably in fossil fuels. Immediately after the separation from the Soviet Union in 1991, the economies of the region experienced severe recessions with sharp declines in production outputs including energy production, resulting in the shrinkage of energy consumption. However, during the second decade of independence CA economies started to show signs of positive growth with significantly more robust growth observed in fossil fuel rich economies.

All five republics in this region are located in dissimilar natural settings with unequal endowments of natural resources. Northern countries such as KAZ, UZB and TUR are located mostly in the vast steppes and deserts and are enormously rich in natural resources. They are able to support their local economies through extensive exports of natural energy resources, which provide them to a certain degree with the ability to make timely maneuvers to in response to economic crises and recessions in the world markets. On the contrary, KYR and TAJ possess relatively limited natural resources with their territories extending mostly to predominantly mountainous areas.

The CAC gained their independence from the Soviet Union in the last decade of the $20^{\text {th }}$ century, and today they are full-fledged sovereign members of the international global community. For centuries they have shared culture, traditions, customs and language, thus representing a single region on the global stage. At different times and centuries, they have represented territorial integrity under different names and different rulers such as Turkestan, Mawarannahr, Baqtria, and Transoxiana, and the area was traditionally home to nomads as well as a sedentary population. In the second half of the $19^{\text {th }}$ century, the region was occupied by the Russian Empire, which was later overturned by the Soviet Socialist movement. After the Soviet Socialists came to power they divided the region into five republics and controlled the region from Moscow, using Moscow's "divide and rule" strategy (Spechler [1]). After the dissolution of the Union of Soviet Socialist Republics (USSR), the five current member states of the CAC emerged as successors to the republic. Notwithstanding the separation, they were considered by Soviet communists as a single whole and a common regional infrastructure was developed to connect the region with other parts of the former USSR. The region represented a single economic subdivision within the "unified economic complex of the USSR" (Spechler [1]). However, the lack of accord and mutual understanding among the newly declared independent states with unnecessary 
ambitions rendered the important common infrastructure to useless and made the prospective smooth transition complicated and arduous.

The size of the region's population is 68.6 million, which is unequally distributed over the region. The vast majority of the population resides in UZB with 31.3 million residents, which has been significantly increasing over the last three decades. KAZ's population is the second largest in the region equaling 17.5 million people, and KAZ has been the highest urbanization rate in the region since the Soviet period due to an extensive industrialization program realized by the communist regime there. The highest population growth rate in the region is seen in TAJ with a greater than 2.2 percent annual growth rate, while this dimension in TUR and KYR demonstrates sluggish changes.

Since gaining independence a quarter of century ago the economies of the CAC have experienced significant structural changes in terms of switching policies from agricultural based economies to industrialized ones. During the first decade of their independence all of them struggled with transitional recession, which had different impacts on each economy, depending on their policies. The least affected by the transitional shock was UZB, thanks to its gradual transition policy, while KAZ and KYR suffered a drastic decline in their gross domestic products (GDP) due to their rapidly changing policies. However, a sharp increase in commodity prices (notably the price of energy fuels) starting in the 2000's significantly benefited the economies of KAZ and TUR, leading to a large upsurge over the last 15 years, with a more than tenfold increase in GDP. However, recurring world financial crises, followed by a sharp drop in commodity prices including those of oil and gas, negatively affected the stable growth of these young, still weak economies.

Many studies including Antonakakisa et al. [2]; Auty [3]-[8]; Barry [9], Franke et al. [10]; and Sachs and Warner [11], have examined the theory of the energy (natural) resource curse or the paradox of plenty in resource rich countries, and argue that economies with abundant natural resources perform relatively poorly, and, therefore, resource abundance has a negative effect on economic growth. Antonakakis, et al. [2] examine the resource curse hypothesis within and between countries for different democratic footprints. They used the panel vector auto-regressive (PVAR) approach to suggest that the hypothesis for developing economies and medium-high income countries that have weak political institutions, oil dependence is not growth-enhancing.

Auty [4] insists that without a developmental state natural resource abundance may impede economic transition by diminishing the urgency of reform and by distorting the economy through Dutch disease effects and also rent-seeking behavior and corruption. Auty [5] discussed the political state and the management of mineral rents in capital surplus economies for Botswana and Saudi Arabia using the data from 1970 to 1994, concludes that the resource curse hypothesis holds for the former country while not for the latter. Auty [6] concludes more generally that the resource curse hypothesis, assuming that the resource rich countries perform poorly in economic ground, holds for resource 
rich countries while not for resource poor ones. Auty [7] discusses the relation between natural resources and the "gradual" reform in UZB and TUR compared with that of China and Vietnam. He shows that resource-rich developing countries rely excessively on natural resource rents, creating macro-economic distortions and delaying necessary economic reform. In UZB and TUR, the scale and ease of natural resource rent extraction has consolidated non-developmental governments and eased the pressure for economic reform, such that the basic wealth-generating assets are being run into the ground.

Barry [9] investigates the so-called Dutch disease in UZB by applying a CGE (computable general equilibrium) model of the effects of foreign investment into UZB's gas sector. He concludes that the gain in the natural gas sector would come at the expense of production and the net exports of the manufacturing, food, textiles and apparel sectors as expressed by the Dutch disease. Sachs and Warner [11] confirm that the curse of natural resources, concluding that resource-abundant countries tend to be high-price economies and that, partly as a consequence, these countries tend to miss-out on export-led growth.

We first examine the roles and values of energy resources in the economic growth of the CAC focusing on the past and current energy policies and strategies through investigating energy data and economic development data during the period 1990-2014. We try to find the causal relationship among energy production, economic growth, energy trade issues, energy prices and so on for various periods by applying regression models as given in Section 3. We believe that the findings of this study provide useful insights into the extent of the impacts of energy production on economic growth in the CAC, and thus help in developing proposals to build future energy strategies. The next section provides a general overview of the economies of the CAC focusing on energy production, and supply and demand in the region, in which we show mathematical models demonstrating the extent of the causal relationship of GDP and energy production. Section 3 discusses issues involving the trade of energy resources with neighboring countries. We also apply econometric multivariate regression models to estimate the impact of trade on economic growth in CA countries. In Section 4, we propose energy policies and strategies for CA countries based upon our regression results. Section 5 discusses future energy strategies for the CAC. Finally we summarize the paper with our policy recommendations.

\section{Economic Growth and Energy Situations in the CAC}

\subsection{Economic Growth and Energy Situations}

The dissolution of the Soviet Union in 1991 and the ensuing disruption of networks caused deep recessions in the economies of the CAC. The disintegration forced these new countries to face realities and challenges in domestic and foreign affairs independently and to build their own strategies for overcoming those challenges. KAZ and KYR introduced open market economies with the large-scale privatization of previously state-owned enterprises and properties 
and immediate trade liberalization, which gave rise to shock, confusion, and chaos during the initial stages of development. On the other hand, UZB and TUR avoided drastic changes by opting for gradual change towards a market economy with a strong state presence (Agzamov et al. [12]; Pomfret [13], [14]). The lack of access to potential world consumer markets and to alternative transportation networks served against the interests of the CAC, impeding the growth and development of trade and the economy. However, a sharp increase in world commodity prices (particularly the price of energy fuels and minerals) from the 2000's onward significantly benefited all the economies of the region, particularly those well-endowed with energy resources, KAZ and TUR. Massive foreign investment in the energy sector of these countries has enabled the extensive exploration and development of oil and natural gas fields. This substantially increased the region's proven hydrocarbon reserves, and, as a result the region became more attractive to the fuel hungry regions of the world.

The relationship between energy consumption and economic growth has been investigated in many studies such as Ahmed and Azam [15]; Apergis and Payne [16], [17], [18]; Asafu-Adjaye [19]; Bildirici and Kayıkçı [20], [21], [22]; Chiou-Wei et al. [23]; Chontanawat et al. [24], Chuanhe et al. [25]; Dogan [26]; Ebohon [27]; Eggoh et al. [28]; Lee [29]; Mudarissov and Lee [30]; Ozturk [31]; Sentürka and Satafa [32]; Sharma [33]; Soares et al. [34]; Soytas and Sari [35]; Tsani [36]; Tugcu et al. [37]; Yuan et al. [38]; and Yu and Hwang [39]). Ozturk [31]) provides an extensive literature survey on the energy (electricity) consumption and economic growth nexus, concluding as a general observation that the results are conflicting and that there is no consensus either on the existence or on the direction of causality between energy (electricity) consumption and economic growth. Ahmed and Azam [15] used a Granger-causality model to show the causal nexus between energy consumption and economic growth for 119 high, middle and low income countries. They confirmed that the relationship between energy consumption and economic growth was based on the "feedback hypothesis" for 18 countries, on the "growth hypothesis" for 25 countries, on the "conservation hypothesis" for 40 countries, and on the "neutrality hypothesis" for 36 countries. In section 4 we show the relationship between energy consumption and economic growth in the form for measuring the impact of GDP, energy production, and FDI (foreign direct investment) on the trade issues given by the export and import.

Apergis and Payne [16] have shown that there is unidirectional causality from energy consumption to economic growth in the short-run, using the data of 11 CIS countries, including the CAC, while bi-directional causality can be seen between energy consumption and economic growth in the long run. In addition, Apergis and Payne [17], [18] have shown that there is bidirectional causality between renewable energy consumption and economic growth in both the short-run and long-run. Also there is bidirectional causality between renewable energy consumption and economic growth in both the short-run and long-run. The relationship between energy consumption and economic growth has been 
investigated for various regions in the world. For the CAC, Bildirici and Kayıkçı [20], [22] have shown that electricity consumption and GDP, and energy consumption and economic growth are all co-integrated for all the CAC; thus, there is a positively bidirectional causality between energy consumption and economic growth in the long run. Also Senturka and Sataf [32], applying the vector error correction model approach for cointegrated panel data, emphasized the bidirectional causality for an interdependent relationship between energy consumption and economic growth. Chuanhe et al. 2015 show that the total energy consumption and GDP in KAZ was given by a "U"-type curve, and the relationship was found to be in a recessional decoupling state because of the economic recession. Mudarissov and Lee [30] also obtained empirical results, showing the existence of unidirectional causalities running from energy consumption to economic growth and from economic growth to energy causality in the long and short terms, respectively.

For Asian countries, Asafu-Adjaye [19] concluded that the results did not support the view that energy and income were neutral with respect to each other with the exception of Indonesia and India, where neutrality was observed in the short-run, Chiou-Wei et al. [23] observed the neutrality hypothesis for the US, Thailand and South Korea and unidirectional causality was seen from economic growth to energy consumption in the Phillippines and Singapore. Lee and Chang [40] found a positive long-run co-integrated relationship between real GDP and energy consumption when the heterogeneous country effect was taken into account, but economic growth and energy consumption lacked short-run causality. For Indonesia, Soares et al. [34] revealed that no directional flow exists from GDP to energy consumption, and also no causal relationship between GDP and energy consumption exists in Indonesia in the long run, although a relationship exists in the short run. However, their tests indicated the presence of a strong statistical relationship between GDP and energy consumption in Indonesia. For China, Yuan et al. [38] found that there exists long-run co-integration among output, labor, capital and energy use at both aggregated and all three disaggregated levels.

For African countries, Dogan [25] found that there was unidirectional causality running from energy use to economic growth in Kenya and no causality linkage between energy consumption and economic growth in Benin, Congo and Zimbabwe, while Ebohon [27] and Eggoh et al. [28] found that there was a simultaneous causal relationship between energy and economic growth for Tanzania and Nigeria, and there exists a long-rung equilibrium relationship among energy consumption, real GDP, prices, labor and capital for 21 African countries.

For advanced countries, Soytas and Sari [36] investigated the energy consumption and GDP causality relationship in G7 countries and emerging markets, discovering bi-directional causality in Argentina, causality running from GDP to energy consumption in Italy and Korea, and from energy consumption to GDP in Turkey, France, Germany and Japan, and thus, energy conservation 
may harm economic growth in the last four countries. Tugcu et al. [37] applied the autoregressive distributed lag approach to the co-integration issue for G7 countries to conclude that there exist bi-directional causality between non-renewable energy consumption and economic growth for each country. Yu and Hwang [39] investigated the causal relationship between GNP and energy consumption, and energy consumption and employment also using the data from 1947 to 1979 with the conclusion that no causal relationship between GNP and energy consumption is found while there is a slight unidirectional flow running from employment to energy consumption.

Chontanawat et al. [24], using data from 1960 to 2000, investigated the causality from energy to GDP for over 100 countries and find that it is more prevalent in developed OECD countries than in developing non-OECD countries. Sharma [33], applying the dynamic panel data model approach to 66 countries data, concluded from his empirical experiments that the relationship between energy and economic growth was mixed while the impact of energy consumption on economic growth was positive for Europe and the Central Asian region. Using 18 developing countries data from 1975 to 2001 Lee [29] concluded that long run and short run causalities run from energy consumption to GDP, but not vice versa. Tsani [36] analyzed the causality between energy consumption and economic growth for Greece, suggesting from his empirical findings that at disaggregated levels of energy consumption there exists a bi-directional relationship between real GDP and industrial/residential energy consumption.

The size of the CAC economy is quite small, equal to only $0.41 \%$ of the world economy (World Bank [41]). KAZ's share in the regional economy is the largest among the CAC with $61 \%$ of the total and its GDP, which experienced a seven-fold increase over the last 15 years, is equal to 184.3 billion US\$ (in current 2015 prices). While there are many reasons behind this strong growth, the key factor is the country's vast endowment of fossil fuels, its energy production growth and energy export expansion coupled with the significant increase of price for energy fuels in the world market. The introduction of a favorable investment policy by the KAZ government in the late 1990s resulted in the extensive inflow of foreign direct investment (FDI) into the gas and energy sectors of its economy with further increases in the production volumes. UZB is the second largest economy in the CAC with a GDP of over 66.7 billion US\$ (in current 2015 US\$). The UZB economy is one which consumes the overwhelming part of its produced energy resources due to the inefficiency of its energy usage and outdated energy infrastructure. Due to its state-led and gradualism approaches UZB failed to attract extensive FDI, which resulted in a linear but stable increase in the size of its GDP over the years. TUR followed its counterpart $\mathrm{KAZ}$ in modernizing its energy sector through extensive FDI and expanding its energy export markets through building alternative export routes. This resulted in more than 14 fold increase in its GDP over 17 years and it became one of the fastest growing economies of the world. 
Table 1 shows the GDP and GDP per capita (GDPC) in years 1998 and 2015, respectively, and the average annual growth of GDP per capita (GDPCG) during the period from 1998 to 2015. From Table 1 we find that these five CAC can be divided into 2 groups: group I consisting of KAZ, UZB and TUR, which shows much larger GDP values, and group II, corresponding to KYR and TAJ, which shows smaller GDP values. We see that group I countries have more than 4 times larger GDP compared with group II countries. Regarding the GDPCG corresponding to the unit increase of GDP, we find that TUR shows the largest average annual increase of 182.99 US $\$$ corresponding to a 1 million US $\$$ increase for GDP. TUR's average annual increase is more than 6 times larger than UZB's, which has the smallest GDPCG at 29.16 US\$. KAZ, with the largest GDP among the CAC, shows an average annual increase of 55.72 US\$, one third that of TUR. We also find that group II countries, which have much smaller GDP compared with group I countries, show rather large average annual increases of 153.90 and 108.12 US\$ for KYR and TAJ, respectively.

Figure 1 and Figure 2 show the trend of GDP and GDP per capita for the CAC during the period from 1993 to 2015. The sharp increase in the GDP

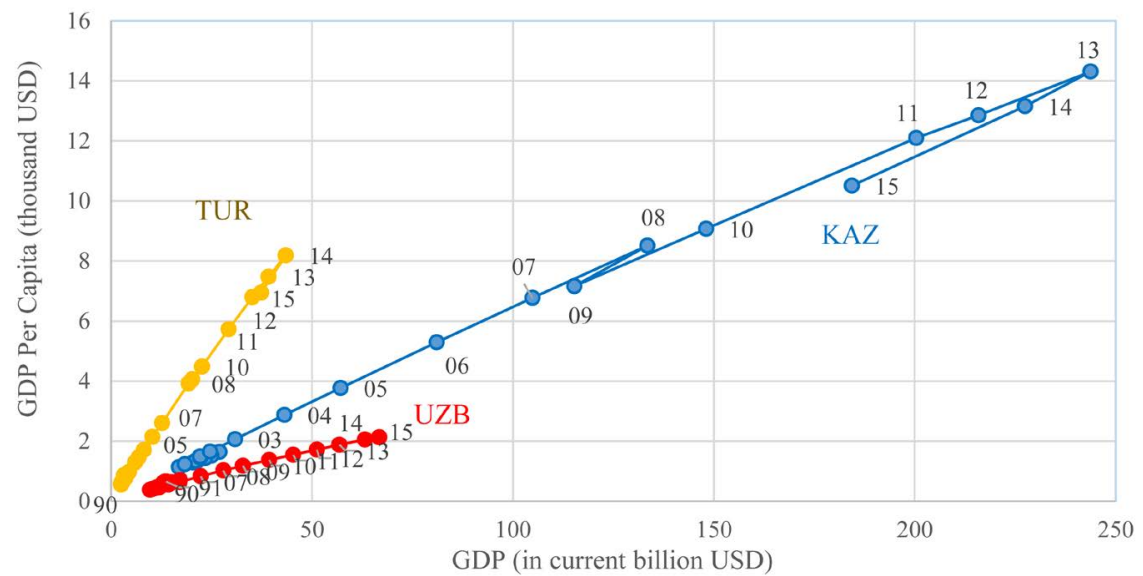

Figure 1. GDP and GDP per capita for the group I countries. Data source: World Development Indicators, The World Bank https://data.worldbank.org/data-catalog/world-development-indicators.

Table 1. GDP, GDP per capita and average growth of GDP per capita.

\begin{tabular}{cccccc}
\hline \multirow{2}{*}{ Country } & \multicolumn{2}{c}{ GDP } & \multicolumn{2}{c}{ GDPC } & GDPCG \\
\cline { 2 - 6 } & 1998 & 2015 & 1998 & 2015 & $1998-2015$ \\
\hline KAZ & $22,135.2$ & $184,360.6$ & 1468.7 & $10,508.4$ & 55.72 \\
UZB & $14,988.9$ & $66,732.8$ & 623.2 & 2132.0 & 29.16 \\
TUR & 2605.6 & $37,334.2$ & 592.8 & 6947.8 & 183.0 \\
KYR & 1645.9 & 6571.8 & 345.1 & 1103.2 & 153.9 \\
TAJ & 1320.1 & 7853.4 & 219.5 & 925.9 & 108.102 \\
\hline
\end{tabular}

GDP: Gross domestic product (current Billion US\$), GDPC: GDP per capita (US\$). GDPCG: Average GDPC growth (US\$/Million US\$). 


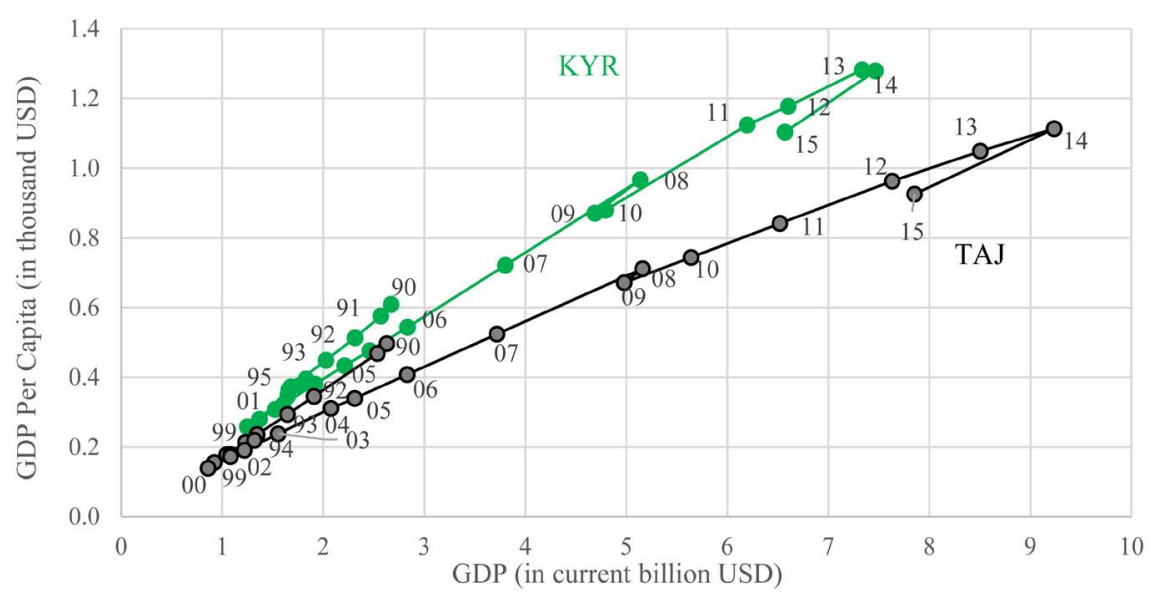

Figure 2. GDP and GDP per capita for group II countries. Data source: World Development Indicators, The World Bank

https://data.worldbank.org/data-catalog/world-development-indicators.

enabled the significant increase of the GDPC in both KAZ and TUR, moving these countries from the low income category to the upper middle income category. Substantial amounts of FDI into the oil and gas sectors targeting exports transformed both KAZ and TUR into fast-growing economies. KAZ became the CAC's economic leader, with a GDP greater than those of its four neighbors combined (Asian Development Bank [42]). Because of the slower growth in the population in KAZ and TUR their GDP per capita (GDPC) indicators increased greatly, which did not happen in the case of UZB, where the population growth is strong ( $1.6 \%$ annual growth).

\subsection{Relationship between Economic Growth and Energy Production}

Regarding measuring the relationship between energy production and economic growth, most studies which have been done so far have focused upon some specific country. Wada [43] measured the dynamic causality between energy production and economic growth in Saudi Arabia, applying an unrestricted vector auto-regression model to the data from 1971 to 2013 and concluding that the evidence of unidirectional Granger-causality from real GDP to per capita energy production is an indication of the relatively lower dependency on energy as stimulant for economic growth, thus implying that an energy conservation policy relating to sustainable energy production can be pursued and sustained in Saudi Arabia without hurting real economic growth. Ahmad and $\mathrm{Du}$ [44] measured the effects of energy production and $\mathrm{CO}_{2}$ emissions on economic growth in Iran using an ARDL approach. They found long-run relationships such that carbon dioxide emissions have a positive relation with economic growth, energy production has a positive effect on the economic growth, and domestic investment has a greater contribution than foreign investment. Sambodo et al. [45] applied a multiobjective optimization modeling technique for obtaining an optimal power expansion program evaluating two conflicting objectives: one for minimizing the 
power generating cost and the other minimizing $\mathrm{CO}_{2}$ emissions in Indonesia. Ozkan et al. [46], using the data for Turkey from 1975 to 2007, found that energy production has a direct relationship with GDP, and it has causality effects. Based on regional analyses of 29 provinces in China, Liu [47] found that energy production negatively impacts economies in Western and Central regions of the country. Also, Peach and Starbuck [48] investigated 33 counties in New Mexico and found that estimated models suggest that oil and gas extraction in New Mexico counties has had a small but positive effect on income, employment and population. Reynolds and Kolodziej [49] applied a Granger causality model to the former Soviet Union's oil production and GDP decline problem, deriving the findings that the fall in the Soviet and former Soviet GDPs in the 1980s and 1990s did not Granger cause the decline in oil production, but decline in oil production did cause the fall in GDP. Bildirici and Kayikci [21] measured the effect of oil production on economic growth in Eurasian countries applying a panel ARDL approach. Their empirical results have shown the necessity to increase oil production for these countries as oil production and economic growth in these countries are cointegrated, thus oil production has a positive effect on economic growth, and economic growth positively effects oil production, and there are bi-directional causalities both in the short-run and the long-run.

Figure 3 and Figure 4 show the relation between GDP and energy production (EPR) in the period 1990-2013 for group I and II countries, respectively. From these figures, we find that all the CAC have similar trends with respect to the relation between GDP and EPR such that both of these two components have downward movement from 1990 until around 1995, then they change to upward movement from around 1995 up to 2013. First, from Figure 3, we find that for countries in group I (KAZ, UZB and TUR), the whole period from 1998 to 2014 can be divided into two periods: the first from 1998 to 2008 and the second from 2009 to 2014, corresponding to "before" and "after" the "Lehman Shock" in 2008. Furthermore, these countries show particularly and clearly the typical

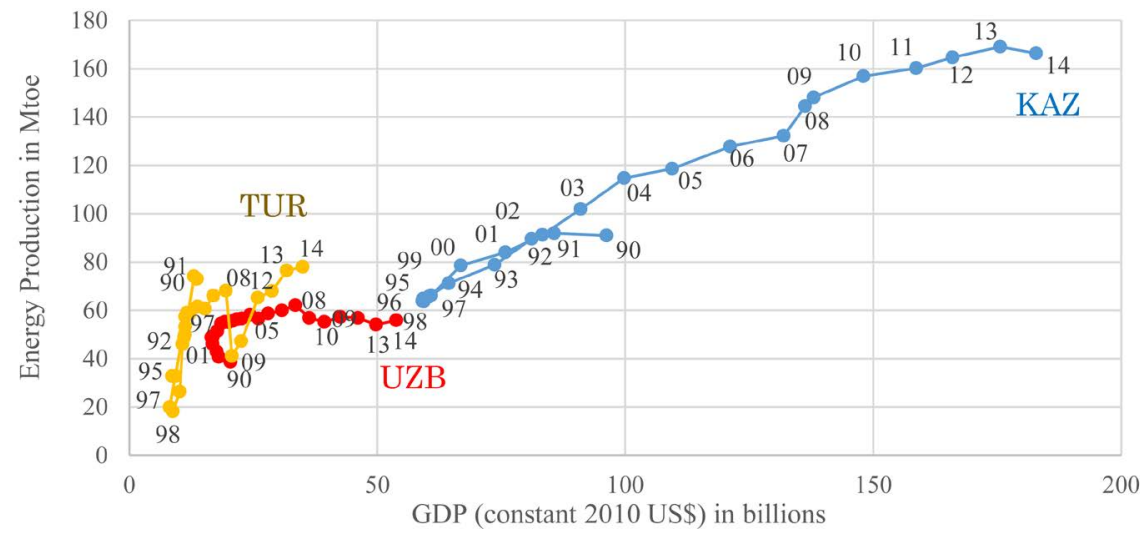

Figure 3. GDP and energy production during 1990-2014 for group I countries. Data source: The IEA, World Development Indicators, The World Bank (2016) https://data.worldbank.org/data-catalog/world-development-indicators, https://www.iea.org/statistics/. 


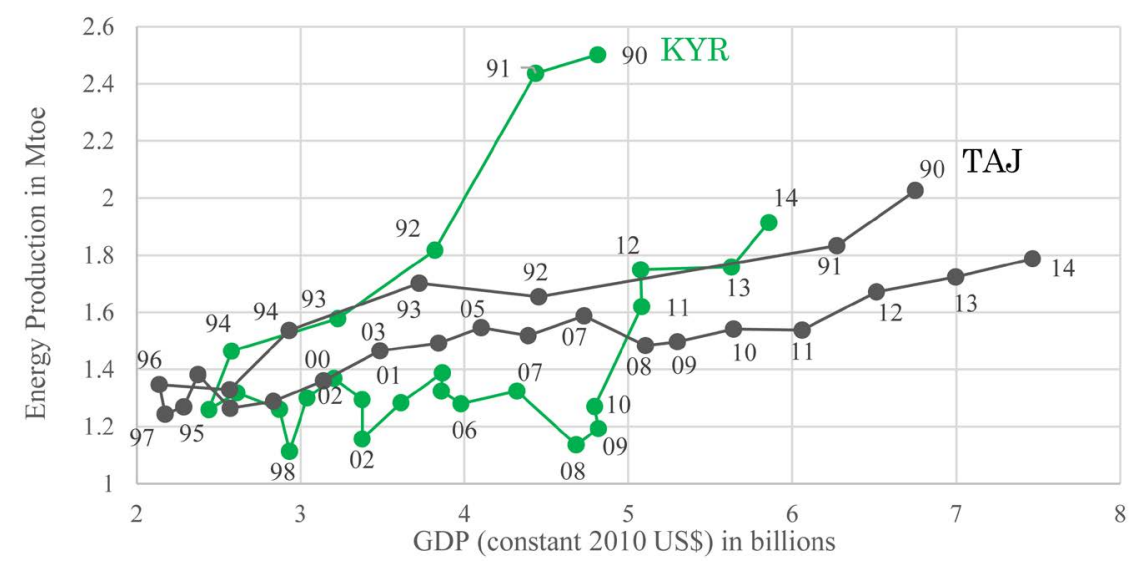

Figure 4. GDP and energy production during 1990-2014 for group II countries. Data source: The IEA, World Development Indicators, The World Bank (2016) https://data.worldbank.org/data-catalog/world-development-indicators, https://www.iea.org/statistics/.

and remarkable difference before and after the economic crisis. We apply modeling techniques in order to measure the difference quantitatively. As seen in Figure 4 group II countries (KYR and TAJ) show very similar trends, while they have much smaller values for both EPR and GDP compared with group I countries. In addition we find that for these two countries in group II, their trends for the relation between EPR and GDP are almost linear for both periods before and after the economic crisis.

Table 2 and Table 3 show the situation of the energy production and consumption by energy resource type in 2014 for the five CAC. From Table 2 and Table 3 we see that regarding energy production group I countries depend upon major fossil energy resources such as oil, natural gas and coal while group II countries depend mostly on hydro power as they have few fossil energy resources. Regarding the energy consumption for these CAC we see that UZB and TUR rely one natural gas for almost $60 \%$ - 70\% of their energy consumption, while KAZ depends on a variety of energy resources such as oil, coal and electricity. We also find that group II countries consume imported oil and coal along with domestically produced electricity.

Regarding the energy production given in Table 2 we find that group I countries dominantly produce almost $98.8 \%$ of the total, while they contribute almost $88.7 \%$ of the total GDP in 2015 . Thus we know that among all the CAC group I countries dominate almost entirely regarding the energy resource production and consumption situation. Of the energy productions amongst group I countries, KAZ's share is the largest at $54.7 \%$ of the total, while UZB's and TUR's shares are $18.4 \%$ and $25.7 \%$, respectively. KAZ's energy production by fossil energy resources are as follows: oil as the largest (50.7\%), then coal (30.0\%) and natural gas (18.8\%), while UZB and TUR mainly depend upon only natural gas at $90.0 \%$ and $83.6 \%$, respectively. This implies that energy resources in KAZ are the most diversified for the three types of fossil energies of oil, natural gas and coal. 
Table 2. Energy production in the CAC (2014). (Unit: Mtoe)

\begin{tabular}{cccccc}
\hline \multicolumn{5}{c}{ Production } \\
\hline \multirow{2}{*}{ KAZ } & Total & Oil & NG & Coal & Hyd. \\
& 166,284 & 84,346 & 32,264 & 49,940 & 711 \\
& $(100)$ & $(50.7)$ & $(18.8)$ & $(30.0)$ & $(0.4)$ \\
UZB & 55,845 & 2975 & 50,271 & 1577 & 1017 \\
& $(100)$ & $(5.3)$ & $(90.0)$ & $(2.8)$ & $(1.8)$ \\
TUR & 77,976 & 12,797 & 65,179 & 0.00 & 0.00 \\
& $(100)$ & $(16.4)$ & $(83.6)$ & $(0.0)$ & $(0.0)$ \\
KYR & 1915 & 82 & 27 & 659 & 1144 \\
& $(100)$ & $(4.3)$ & $(1.4)$ & $(34.4)$ & $(59.7)$ \\
TAJ & 1788 & 25 & 3 & 384 & 1376 \\
& $(100)$ & $(1.4)$ & $(0.2)$ & $(21.5)$ & $(77.0)$ \\
\hline
\end{tabular}

Table 3. Energy consumption in the CAC (2014). (Unit: Mtoe)

\begin{tabular}{ccccccc}
\hline \multicolumn{7}{c}{ Consumption } \\
\hline \multirow{2}{*}{ KAZ } & Total & Oil & NG & Coal & Elec. & Hyd. \\
& 36,598 & 10,404 & 2823 & 10,621 & 5925 & 6803 \\
& $(100)$ & $(29.0)$ & $(8.0)$ & $(29.0)$ & $(16.0)$ & $(19.0)$ \\
UZB & 30,810 & 2605 & 21,323 & 562 & 3944 & 2354 \\
& $(100)$ & $(8.0)$ & $(69.0)$ & $(2.0)$ & $(13.0)$ & $(8.0)$ \\
& & & & & & \\
TUR & 17,827 & 6187 & 10,444 & 0.00 & 954 & 235 \\
& $(100)$ & $(35.0)$ & $(59.0)$ & $(0.0)$ & $(5.0)$ & $(1.0)$ \\
KYR & 3106 & 1193 & 150 & 583 & 945 & 232 \\
& $(100)$ & $(38.0)$ & $(5.0)$ & $(19.0)$ & $(30.0)$ & $(7.0)$ \\
\multirow{2}{*}{ TAJ } & 2533 & 875 & 188 & 390 & 1055 & 25 \\
& $(100)$ & $(35.0)$ & $(7.0)$ & $(15.0)$ & $(42.0)$ & $(1.0)$ \\
\hline
\end{tabular}

The current situation of the energy consumption in the CAC in Table 3 shows that KAZ's share is the largest (40.3\%), while UZB and TUR have $33.9 \%$ and $19.6 \%$, respectively. We see that KAZ's share is larger for energy production than consumption. We find that the production share is larger than the consumption share for KAZ and TUR while UZB's case is the opposite. This means that KAZ and TUR are production dominating while UZB is, on the other hand, consumption dominating. This can be recognized by comparing the production/consumption ratio: KAZ and TUR are 4.54 and 4.37, respectively, much larger than UZB at 1.81. Looking at the structure of the energy consumption for these three group I countries, we see that KAZ, which has a diversified structure, shows a small share of $8.0 \%$ for natural gas. This implies that KAZ intends to produce and export natural gas strategically rather than consuming it domestically.

\subsection{Mathematical Model Analysis}

We investigate the upward trend in more detail by applying the following ma- 
thematical model to these CAC data individually.

$$
y=a\left(x-x_{0}\right)^{b}+y_{0}
$$

where $x$ and $y$ indicate GDP and EPR, respectively, and $x_{0}$ and $y_{0}$ are initial values for GDP and EPR, respectively, in each corresponding period. $a$ and $b$ are parameters. The above model can be applied to the data with nondecreasing trend for both variables $x$ and $y$.

The regressions results for estimating the parameters $a$ and $b$, and coordinates $x_{0}$ and $y_{0}$ corresponding to the initial points are given in Table 4 and Table 5, in which period I indicates the period starting from the corresponding year given by $x_{0}$ and $y_{0}$ in period I up to the next corresponding year in period II while period II indicates the period starting from the corresponding year given by $x_{0}$ and $y_{0}$ in period II up to the latest year 2014. As the above mathematical model can be applied to the cases such that the historical trend of both variables $x$ and $y$ is nondecreasing, we delete two cases: one case for period II for UZB and one

Table 4. Regressions results for group I countries.

\begin{tabular}{cccccc}
\hline Country & \multicolumn{2}{c}{ KAZ } & UZB & \multicolumn{2}{c}{ TUR } \\
\hline Period & I & II & I & I & II \\
\hline$x_{0}$ & 59.28 & 137.98 & 18.52 & 8.75 & 20.68 \\
$y_{0}$ & 64.80 & 148.05 & 54.54 & 18.11 & 41.11 \\
$\log a$ & 0.0550 & 1.0539 & 0.6302 & 1.1856 & 0.0429 \\
$t$-value & $(0.6023)$ & $(7.3410)$ & $(17.9640)$ & $(9.8293)$ & $(0.1942)$ \\
$P$-value & $(0.5636)$ & $(0.0018)$ & $(0.0000)$ & $(0.0000)$ & $(0.8554)$ \\
$\log b$ & 0.9933 & 0.4626 & 0.3533 & 0.5980 & 1.2589 \\
$t$-value & $(16.1874)$ & $(6.4632)$ & $(8.4688)$ & $(3.1306)$ & $(7.1884)$ \\
$P$-value & $(0.0000)$ & $(0.0029)$ & $(0.0000)$ & $(0.0140)$ & $(0.0019)$ \\
$R^{2}$ & 0.9703 & 0.9126 & 0.8885 & 0.5505 & 0.9281 \\
\hline
\end{tabular}

Table 5. Regressions results for group II countries.

\begin{tabular}{cccc}
\hline Country & KYR & \multicolumn{2}{c}{ TAJ } \\
\hline Period & II & I & II \\
\hline$x_{0}$ & 4.82 & 2.17 & 5.29 \\
$y_{0}$ & 1.19 & 1.24 & 1.49 \\
$\log a$ & -1.8627 & -0.8706 & -0.0030 \\
$t$-value & $(-3.4211)$ & $(-9.9199)$ & $(-0.1104)$ \\
$P$-value & $(0.0267)$ & $(0.0000)$ & $(0.9173)$ \\
$b$ & 4.0331 & 0.7574 & 0.3491 \\
$t$-value & $(2.6548)$ & $(3.8693)$ & $(7.6937)$ \\
$P$-value & $(0.0566)$ & $(0.0037)$ & $(0.0015)$ \\
$R^{2}$ & 0.6379 & 0.6245 & 0.9367 \\
\hline
\end{tabular}


case for period I for KYR among all the combinations of CAC and time periods. Thus, the numerical regression results are shown in Table 4 and Table 5. We find that all these results show very high goodness of fit for the above model with high $R^{2}$ of 0.55 up to 0.97 . We know that parameter $b$ in (1) indicates the GDP elasticity with respect to the energy production EPR. As long as the parameter $b$ is concerned, we can give reasonable interpretation in case that both variables GDP and EPR are nondecreasing. Regarding the estimates for parameter $b$ for these major countries KAZ, UZB and TUR, we find that KAZ's estimate 0.993 is very close to 1 and the largest among these three countries. From (1) we can write as follows.

$$
b=\frac{x-x_{0}}{y-y_{0}} \frac{\mathrm{d} y}{\mathrm{~d} x}
$$

Thus it implies that in KAZ energy production EPR grows almost proportionally to the GDP growth, i.e., EPR grows almost $1 \%$ corresponding to the unit $\%$. growth of the GDP. UZB shows the smallest elasticity with a 0.353 increase of EPR corresponding to the unit \%. Growth of the GDP, while TUR shows an intermediate elasticity of 0.598 before the economic crisis. After the economic crisis, we find that in the two major countries KAZ and UZB, the estimates for parameter $b$ show decreases compared with those for period I before the economic crisis, while in TUR, the estimate for parameter $b$ shows an increase. The parameter estimate for $b$ in KAZ shows a decrease from 0.993 to 0.463 , while UZB also shows a decrease from positive 0.353 to negative -0.264 . TUR is the only country that shows an increase from 0.598 to 1.259 as the increase during the second period is higher than during the first period as seen in Table 5. KYR's parameter estimate for $b$ shows a very large elasticity value of 4.0 as the country attained a rapid increase of energy production corresponding to the GDP increase. On the other hand, TAJ shows a slow increase for the energy production during both period I and II.

\section{Trade Issues of Energy Resources for the CAC}

\subsection{Trade Structure of Energy Resources and Services}

Table 6 shows the GDP, export (EXP), energy production (EPR) and total primary energy supply (TPES) for the CAC in 2014. From Table 6 we find that $\mathrm{KAZ}$, UZB and TUR corresponding to group I in the CAC dominate all items shares such as GDP, EXP, EPR and TPES compared with group II countries of KYR and TAJ. As of 2014, KAZ holds the largest share in the regional production and supply of energy resources with $55.8 \%$ and $51.9 \%$, respectively. The size of the TPES of KAZ is half of its energy production, which indicates that its export volume of energy resources is large. Correspondingly, KAZ's GDP demonstrates the highest share in the region $(68.6 \%)$, which is 33 times larger than KYR or TAJ's GDP. Regarding the EPR, the second largest share in the region belongs to TUR (25.2\%), and its total energy production volume is three times larger than its total primary energy supply, which tells us that two thirds of TUR 
Table 6. GDP, Export, Energy production and TPES of the CAC in 2014.

\begin{tabular}{ccccc}
\hline Country & GDP & EXP & EPR & TPES \\
\hline KAZ & $243.77(68.6)$ & $90.72(71.1)$ & $169.07(55.8)$ & $81.54(51.9)$ \\
UZB & $56.79(16.0)$ & $15.35(12.0)$ & $54.12(17.9)$ & $42.93(27.3)$ \\
TUR & $39.19(11.0)$ & $16.80(13.2)^{*}$ & $76.53(25.2)$ & $26.26(16.7)$ \\
KYR & $7.33(2.1)$ & $3.10(2.4)$ & $1.75(0.6)$ & $3.94(2.5)$ \\
TAJ & $8.50(2.4)$ & $1.63(1.3)$ & $1.72(0.6)$ & $2.45(1.6)$ \\
Total & $355.61(100)$ & $127.60(100)$ & $303.21(100)$ & $157.13(100)$ \\
\hline
\end{tabular}

GDP: Gross Domestic Product (constant 2005 Billion US\$), EXP: Export (current Billion US\$), EPR: Energy Production (Million Tons of Oil Equivalent), TPES: Total Primary Energy Supply (Million Tons of Oil Equivalent), Figures in parentheses indicate percentages. ${ }^{*}$ This data represents TUR's merchandise export only. Source: IEA, World Bank Database.

energy resources are exported to external markets. However, its GDP share (11.0\%) and TPES share (16.7\%) in the region are smaller than those of UZB (16.0\% and $27.3 \%$, respectively). UZB has a different portfolio than its group I counterparts with minor variances in production and the local supply of energy due to the gradual depletion of its reserves, weak production and high local demand of its energy resources. KYR and TAJ have very small shares in all area of comparison.

The location of the CAC in the heart of the Eurasian continent but without direct transportation routes to the European and Asian markets and without direct access to the sea has been significantly preventing the CAC from utilizing the opportunities of promoting trade with world markets on full scale. The only available route, leading to the European market through Russia, restricted opportunities for the CAC to develop their trade relations with the main consumer markets, due to price dictation by Russia, which used this lever as an instrument of political influence. Figure 5 shows the export destinations from the CAC in 2014. Countries with extensive export potential such as KAZ and TUR could build alternative routes for the export of their main export items-oil and gas. In 2011, a gas pipeline connecting TUR, UZB and KAZ with China was constructed and put into operation successfully, which significantly increased the export potential of all three countries. In addition, an oil pipeline, built between KAZ and China earlier in 2008, could also enormously increase export volumes of KAZ oil to the Chinese market. Furthermore, TUR successfully built a gas pipeline to Iran, enabling TUR to export its natural gas not only to Iran but also to Turkey, thus making TUR less dependent on Russia.

In Figures 6-10 we show the export-import structure consisting of goods and services for each of the CAC during the period from 2002 to 2015. For each country, each year's data consist of two data points, one corresponding to the export and import of the total export-import data in the $x$-coordinate and $y$-coordinate, respectively, while the other indicates the export and import data for the goods in the $x$-coordinate and $y$-coordinate, respectively. In Figures $6-10$, the points on the dense line correspond to the former total export-import 


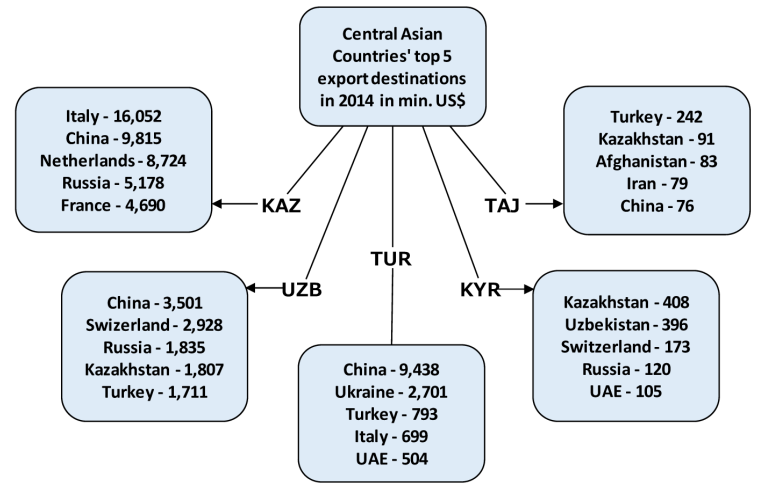

Figure 5. Exporting destinations for the CAC. Data source: International Trade Center http://www.intracen.org/ (report for KAZ, UZB, TUR, KYR, and TAJ)

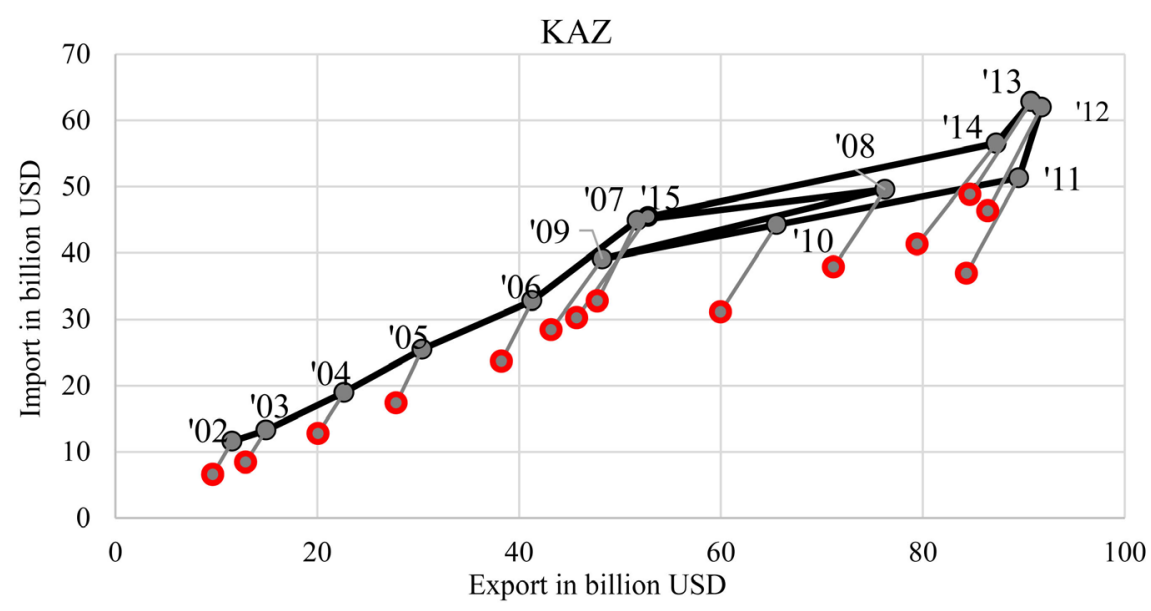

Figure 6. Export-import structure (KAZ, 2002-2015).

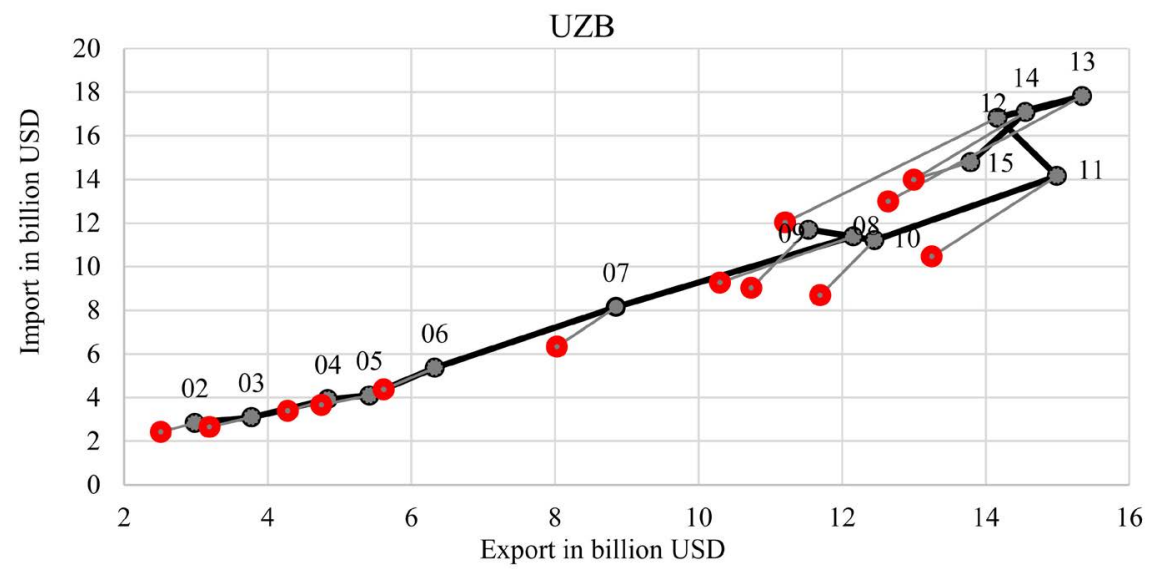

Figure 7. Export-import structure (UZB, 2002-2015).

data for each year and each country, while the other points connected with these total export-import data points separately by each light line indicate the goods export-import data. Additionally, in Figures 6-10 each branch line for each year and each country corresponds to the service export-import data; namely, the horizontal $\mathrm{x}$-coordinate corresponding to the branch line indicates the service 


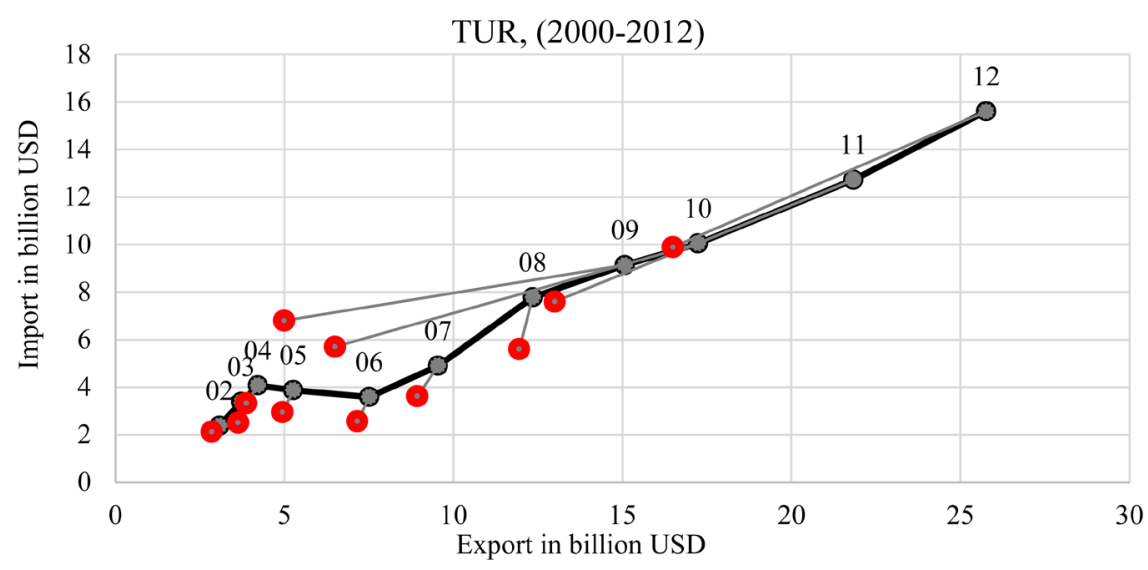

Figure 8. Export-import structure (TUR, 2002-2012).

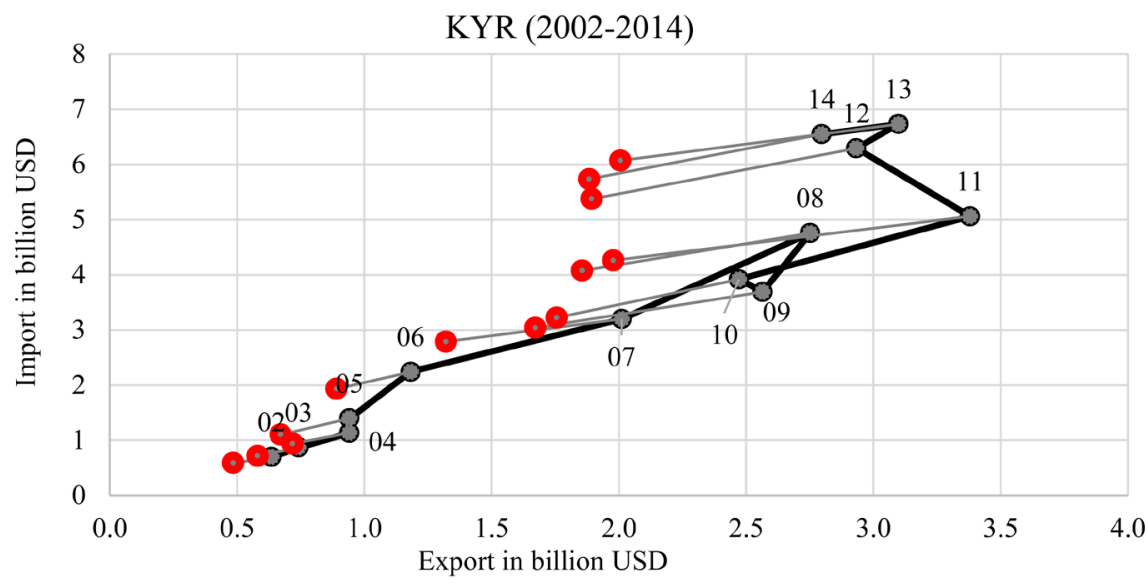

Figure 9. Export-import structure (KYR, 2002-2014).

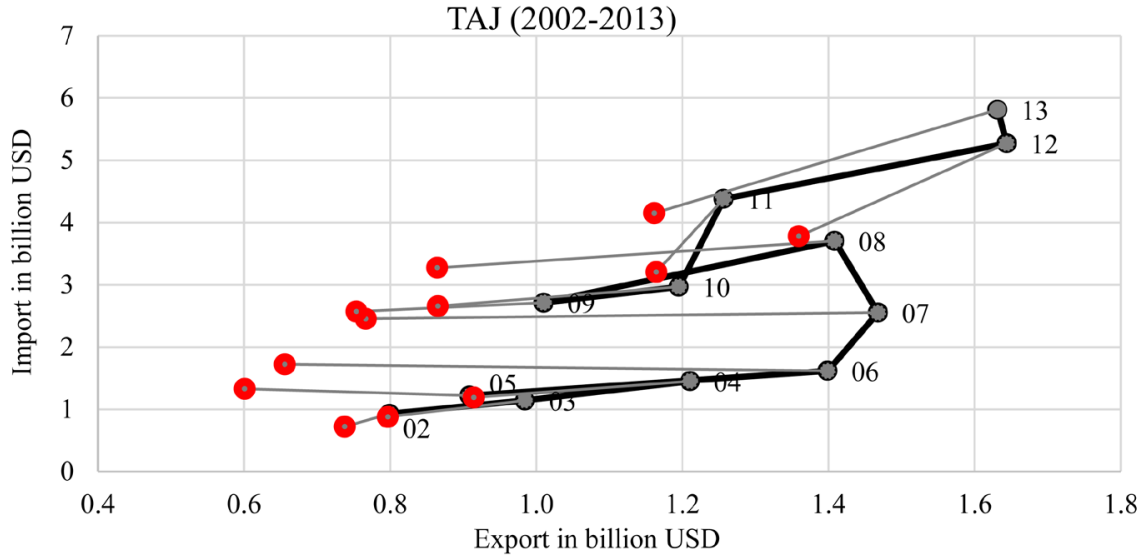

Figure 10. Export-import structure (TAJ, 2002-2013). Data source (Figures 4(a)-(e)): World Development Indicators, The World Bank, (2016)

https://data.worldbank.org/data-catalog/world-development-indicators, UN Comtrade Database (2016) https://comtrade.un.org/.

export, while the vertical $y$-coordinate corresponding to the branch indicates the service import data. Thus the shorter branch line implies that the quantity of the 
service export-import is much smaller than that of the goods export-import. In other words, the total export-import is dominantly occupied by goods.

We find that the economies of all five CAC heavily rely on commodity exports. For the group I countries of KAZ, UZB and TUR, the main items for export are energy resources such as natural gas, crude oil and fuels, while the group II countries of KYR and TAJ heavily rely on aluminum and gold export. Due to the significant rise of energy prices in the world market over the last 15 years and the extensive increase of the energy extraction volumes of group I countries, they have been converted to energy export dependent economies, while economies of group II countries significantly rely on the imports of goods. Since the data for the export and import of goods and services are not available separately for TUR and UZB, we used an approximation method to find the share of services by subtracting the export and import of merchandise from the total export and import for goods and services, thus drawing the corresponding figures. Figures 6-10 demonstrate these data for the period between 2002-2015 (KAZ, UZB), 2002-2012 (TUR), 2002-2014 (KYR), and 2002-2014 (TAJ), respectively, for each country in the CAC.

KAZ demonstrates a positively balanced increasing trend of exports and imports for both goods and services with a growing share of services in its portfolio. However, the ratios for the export of goods and services in KAZ in 2002 were $84 \%$ to $16 \%$, respectively, which changed over the following 10 -year period towards a decrease of service's share to $6 \%$. In terms of the real amount, however, it increased almost three times. The ratio of goods and services import also went through significant change in proportion from $57 \%$ and $43 \%$ in 2002 to $75 \%$ and $25 \%$ in 2012, respectively. KAZ's export-import structure had been stably growing during the period from 2002 to 2012 in both exports and imports, then after 2012 up to 2015 it has been decreasing again following the past trend similarly. Also, we see that the proportion of the goods exports and imports compared with the total exports and imports is very stable during the period from 2002 to 2012 and after 2012 also as the slope of each branch for each year is very similar. We also see that the service exports and imports increase each year as the branch line is getting longer year by year. Moreover, as we see that the growth curve of the export-import structure increases in convex form from 2010 to 2012. This indicates that the increase of exports is much faster than that of imports; however, the opposite is observed from 2013 to 2015; i.e., we see a concave form, which implies the decrease of exports is much faster.

UZB's trend shows a gradual increase in the share of services in both categories of exports and imports from $16 \%$ and $15 \%$ in 2002 to $21 \%$ and $29 \%$ in 2012 , respectively. UZB's export-import structure grows in a convex form from 2010 to 2013, which means the increase of exports is much faster than that of imports, however, the opposite is observed from 2013 to 2015, when we see the concave form, which implies the decrease of imports is much faster. Also, we see that especially after the year 2008, the branch line is getting much longer rapidly. 
The data for TUR illustrates a significant change towards the increase of services in both categories from $7 \%$ to $36 \%$ and from $11 \%$ to $37 \%$ in a decade, respectively. TUR's export-import structure grows almost linearly. We find a typical fact that the branch line gets drastically longer from the year 2007 with its slope much flatter than before. This means that after 2007 service export and import grow very rapidly. Especially, the former, service exports, grows much more drastically than imports.

For group II countries, their trends demonstrate the significant increase of export services from $24 \%$ to $35 \%$ and from $8 \%$ to $17 \%$ from 2002 to 2012 , respectively, while the import services category shows insignificant change. For both KYR and TAJ, we find from Figure 6 and Figure 7 that their data points are above the 45 degree line, which shows they are different from group I countries. Thus, in KYR and TAJ we see that their goods exports are very small compared with the service exports, and moreover their goods import is very large, occupying most of their total imports.

\subsection{Regression Model Analysis}

The relationship between the energy resource exports/imports and the GDP of these countries is well demonstrated in the graph, which shows the trend of their GDP and energy exports/imports (see Figures 6-10). KYR and TAJ are energy import dependent countries, partially relying on their hydro energy resources. KYR imports almost half of its consumed energy resources from neighboring countries, while TAJ's energy imports constitute $22 \%$ of its total consumption as of 2013.

We define the following regression model in order to investigate the trade issue related structural characteristics for each country in the CAC.

$$
y_{t}=a_{0}+\sum_{i \in N} a_{i} x_{i t}+u_{t}, t \in T
$$

where $N=\{1,2, \cdots, 5\}$ and $T$ indicate the set of independent variable indices and the set of periods, respectively, for each country data, and $u_{t}$ is an error term. In the above formula, we define a dependent variable $y_{t}$ as the trade issue related variable expressed by using $E$ : export and $I$ : import. The independent variables are $x_{1}$ : GDP, $x_{2}$ : energy production, $x_{3}$ : FDI (foreign direct investment), $x_{4}$ : oil price, and $x_{5}$ : natural gas price, respectively. In order to explain the behavior of the trade issue related variables export and import, we have selected variables such as GDP, energy production, FDI and energy prices to be enough.

We show the relation between trade activity and several determining factors that have various degrees of impact. We express the trade activity by using three types of indicators; "Export - Import" denoted by $E-I$, "Export" denoted by $E$ and "Export - Import" denoted by $E+I$. Tables 7-9 show the regression results for the three cases with dependent variables $E-I, E$ and $E+I$, respectively. Each of these dependent variables $E-I, E$ and $E+I$ implies the trade balance, export capability and total volume of trade, respectively. The regression models' results given in Tables 7-9 all have common independent variables; Gross Domestic 
Table 7. Regression results for the trade balance $(E-I)$.

\begin{tabular}{|c|c|c|c|c|c|}
\hline Country & KAZ & UZB & TUR & KYR & TAJ \\
\hline Period & $1992-2014$ & $1992-2014$ & $1993-2012$ & $1993-2014$ & $1992-2013$ \\
\hline Const. $\left(\mathrm{a}_{0}\right)$ & $14085.6^{\star *}$ & -2019.71 & $-1895.76^{\star * *}$ & $1310.99^{*}$ & -174.23 \\
\hline (t-value) & (2.597) & $(-1.266)$ & $(-4.817)$ & $(1.888)$ & $(-0.3163)$ \\
\hline (P-value) & $(0.0188)$ & $(0.2227)$ & $(0.0002)$ & $(0.0770)$ & $(0.7550)$ \\
\hline $\operatorname{GDP}\left(a_{1}\right)$ & $-0.1636^{\star \star}$ & $-0.0676^{* * *}$ & -0.0770 & $-0.574^{* * *}$ & $-0.4286^{* * *}$ \\
\hline (t-value) & $(-2.1900)$ & $(-3.2055)$ & $(-0.905)$ & $(-3.7273)$ & $(-4.3762)$ \\
\hline (P-value) & $(0.0428)$ & $(0.0051)$ & $(0.3807)$ & $(0.0018)$ & $(0.0004)$ \\
\hline $\operatorname{EPR}\left(a_{2}\right)$ & $0.1847^{\star}$ & 0.0427 & $0.0392^{* * *}$ & -0.4398 & 0.5656 \\
\hline (t-value) & $(2.031)$ & (1.2599) & (3.0429) & $(-0.8410)$ & $(1.3962)$ \\
\hline (P-value) & $(0.0581)$ & $(0.2247)$ & $(0.0080)$ & $(0.4127)$ & $(0.1817)$ \\
\hline $\operatorname{FDI}\left(a_{3}\right)$ & -0.2857 & $2.0367^{* * *}$ & $0.9455^{\star * *}$ & 1.5291 & -0.4248 \\
\hline (t-value) & $(-0.7608)$ & $(5.4518)$ & $(4.1971)$ & $(1.7442)$ & $(-0.8723)$ \\
\hline (P-value) & $(0.4572)$ & $(0.0000)$ & $(0.0008)$ & $(0.1002)$ & $(0.3959)$ \\
\hline $\operatorname{OLP}\left(a_{4}\right)$ & -45.32 & -10.7516 & $92.10^{* * *}$ & -5.2187 & -11.592 \\
\hline (t-value) & $(-0.2639)$ & $(-0.8939)$ & $(4.226)$ & $(-0.5116)$ & $(-1.6717)$ \\
\hline (P-value) & $(0.7951)$ & $(0.3838)$ & $(0.0008)$ & $(0.6158)$ & $(0.1140)$ \\
\hline $\operatorname{NGP}\left(a_{5}\right)$ & $2000.19^{* *}$ & $214.73^{*}$ & $-480.91^{* * *}$ & 38.20 & 37.18 \\
\hline (t-value) & $(2.2765)$ & $(1.9291)$ & $(-3.9759)$ & $(0.6342)$ & $(1.0304)$ \\
\hline (P-value) & $(0.0360)$ & $(0.0705)$ & $(0.0010)$ & $(0.5348)$ & $(0.3181)$ \\
\hline $\mathrm{R}^{2}$ & 0.9344 & 0.9229 & 0.9924 & 0.9685 & 0.9923 \\
\hline $\operatorname{adj} . \mathrm{R}^{2}$ & $(0.8731)$ & $(0.8519)$ & $(0.9849)$ & $(0.9381)$ & $(0.9847)$ \\
\hline
\end{tabular}

Table 8. Regression results for the export capability $(E)$.

\begin{tabular}{cccccc}
\hline Country & KAZ & UZB & TUR & KYR & TAJ \\
\hline Period & $1992-2014$ & $1992-2014$ & $1993-2012$ & $1993-2014$ & $1992-2013$ \\
\hline Const. $\left(\mathrm{a}_{0}\right)$ & $8707.42^{* *}$ & 2565.51 & $-646.04^{*}$ & $1149.77^{* * *}$ & $1785.93^{* *}$ \\
$(\mathrm{t}-$ value $)$ & $(2.381)$ & $(0.9802)$ & $(-1.9249)$ & $(3.0450)$ & $(2.4603)$ \\
$(\mathrm{P}-\mathrm{value})$ & $(0.0292)$ & $(0.3407)$ & $(0.0747)$ & $(0.0077)$ & $(0.0256)$ \\
GDP $\left(\mathrm{a}_{1}\right)$ & -0.0569 & $0.1078^{* * *}$ & $0.4851^{* * *}$ & $0.3456^{* * *}$ & 0.1232 \\
$(\mathrm{t}-\mathrm{value})$ & $(-1.1293)$ & $(3.1168)$ & $(6.6815)$ & $(4.1252)$ & $(0.9547)$ \\
$(\mathrm{P}-\mathrm{value})$ & $(0.2742)$ & $(0.0062)$ & $(0.0000)$ & $(0.0007)$ & $(0.3539)$ \\
EPR $\left(\mathrm{a}_{2}\right)$ & $0.3159^{* * *}$ & -0.0373 & $0.0402^{* * *}$ & $-0.9552^{* * *}$ & -0.8650 \\
$(\mathrm{t}-\mathrm{value})$ & $(5.1523)$ & $(-0.6708)$ & $(3.6609)$ & $(-3.3578)$ & $(-1.6200)$ \\
$(\mathrm{P}-\mathrm{value})$ & $(0.0001)$ & $(0.5113)$ & $(0.0020)$ & $(0.0040)$ & $(0.1247)$ \\
FDI $\left(\mathrm{a}_{3}\right)$ & 0.1672 & $1.7502^{* *}$ & $0.7984^{* * *}$ & 0.5587 & 0.2056 \\
$(\mathrm{t}-\mathrm{value})$ & $(0.6601)$ & $(2.8563)$ & $(4.1560)$ & $(1.1717)$ & $(0.3204)$ \\
$(\mathrm{P}$-value $)$ & $(0.5180)$ & $(0.0109)$ & $(0.0009)$ & $(0.2584)$ & $(0.7527)$ \\
\hline
\end{tabular}




\begin{tabular}{cccccc} 
Continued & \multicolumn{7}{c}{} \\
\hline OLP $\left(\mathrm{a}_{4}\right)$ & 84.9838 & $66.5552^{* * *}$ & $46.6434^{* *}$ & $10.2319^{*}$ & 0.7323 \\
$(\mathrm{t}-$-value $)$ & $(0.7338)$ & $(3.3738)$ & $(2.5100)$ & $(1.8442)$ & $(0.0801)$ \\
$(\mathrm{P}-$ value $)$ & $(0.4731)$ & $(0.0036)$ & $(0.0249)$ & $(0.0837)$ & $(0.9371)$ \\
$\mathrm{NGP}\left(\mathrm{a}_{5}\right)$ & $2000.81^{* * *}$ & 7.8001 & $-447.59^{* * *}$ & -34.041 & -19.6245 \\
$(\mathrm{t}-\mathrm{value})$ & $(3.3775)$ & $(0.0427)$ & $(-4.3395)$ & $(-1.0388)$ & $(-0.4126)$ \\
$(\mathrm{P}-\mathrm{value})$ & $(0.0036)$ & $(0.9664)$ & $(0.0006)$ & $(0.3143)$ & $(0.6853)$ \\
$\mathrm{R}^{2}$ & 0.9876 & 0.9864 & 0.9988 & 0.9879 & 0.7498 \\
adj.R $\mathrm{R}^{2}$ & $(0.9754)$ & $(0.9730)$ & $(0.9976)$ & $(0.9761)$ & $(0.5623)$ \\
\hline
\end{tabular}

Table 9. Regression results for the trade volume $(E-I)$.

\begin{tabular}{|c|c|c|c|c|c|}
\hline Country & KAZ & UZB & TUR & KYR & TAJ \\
\hline Period & $1992-2014$ & $1992-2014$ & $1993-2012$ & $1993-2014$ & $1992-2013$ \\
\hline Const. $\left(\mathrm{a}_{0}\right)$ & 3329.22 & 7150.74 & 603.68 & $988.5480^{* *}$ & $3746.09^{* *}$ \\
\hline (t-value) & $(0.5334)$ & $(1.3238)$ & $(1.1584)$ & $(2.2257)$ & $(2.4302)$ \\
\hline (P-value) & $(0.6006)$ & $(0.2031)$ & $(0.2660)$ & $(0.0407)$ & $(0.0272)$ \\
\hline $\operatorname{GDP}\left(a_{1}\right)$ & 0.0497 & $0.2834^{* * *}$ & $1.0471^{* * *}$ & $1.2653^{\star \star \star}$ & $0.6751^{\star *}$ \\
\hline (t-value) & $(0.5789)$ & (3.9677) & $(9.2897)$ & (12.8396) & $(2.4626)$ \\
\hline (P-value) & $(0.5702)$ & $(0.0009)$ & $(0.0000)$ & $(0.0000)$ & $(0.0255)$ \\
\hline $\operatorname{EPR}\left(a_{2}\right)$ & $0.4471^{\star * *}$ & -0.1174 & $0.0412^{* *}$ & $-1.4706^{* * *}$ & $-2.2957^{\star}$ \\
\hline (t-value) & $(4.2721)$ & $(-1.0224)$ & $(2.4174)$ & $(-4.3946)$ & $(-2.0246)$ \\
\hline (P-value) & $(0.0005)$ & $(0.3209)$ & $(0.0298)$ & $(0.0004)$ & $(0.0599)$ \\
\hline $\operatorname{FDI}\left(a_{3}\right)$ & 0.6201 & 1.4637 & $0.6513^{* *}$ & -0.4116 & 0.8361 \\
\hline (t-value) & $(1.4345)$ & $(1.1575)$ & $(2.1835)$ & $(-0.7338)$ & $(0.6134)$ \\
\hline (P-value) & $(0.1695)$ & $(0.2631)$ & $(0.0465)$ & $(0.4736)$ & $(0.5481)$ \\
\hline $\operatorname{OLP}\left(a_{4}\right)$ & 215.2879 & $143.826^{* * *}$ & 1.1887 & $25.6827^{* * *}$ & 13.0566 \\
\hline (t-value) & $(1.0891)$ & $(3.5338)$ & $(0.0412)$ & $(3.9353)$ & $(0.6727)$ \\
\hline (P-value) & $(0.2913)$ & $(0.0025)$ & $(0.9677)$ & $(0.0011)$ & $(0.5107)$ \\
\hline $\operatorname{NGP}\left(a_{5}\right)$ & $2001.44^{*}$ & -199.131 & $-414.28^{\star *}$ & $-106.29^{\star *}$ & -76.42 \\
\hline (t-value) & (1.9793) & $(-0.5285)$ & $(-2.5868)$ & $(-2.7576)$ & $(100.9869)$ \\
\hline (P-value) & $(0.0642)$ & $(0.6039)$ & $(0.0215)$ & $(0.0140)$ & $(0.4601)$ \\
\hline $\mathrm{R}^{2}$ & 0.9929 & 0.9867 & 0.9988 & 0.9982 & 0.9684 \\
\hline $\operatorname{adj} . \mathrm{R}^{2}$ & $(0.9860)$ & $(0.9732)$ & $(0.9976)$ & $(0.9964)$ & $(0.9378)$ \\
\hline
\end{tabular}

Products (GDP, $10^{9}$ US\$: BUSD), Energy Production (EPR, $10^{9}$ US\$: BUSD, Foreign Direct Investment (FDI, 10 US\$), Oil Price (OLP, US\$/barrel), and Natural Gas Price ( $N G P$, US $\$ / B C M)$.

From these regression results we find the following facts and new insights. Firstly, $G D P$ has slightly negative impacts on the trade balance $(E-I)$ while it 
has mostly significantly positive impacts on both export $(E)$ and total trade volume $(E+I)$. The slightly negative impacts on the trade balance $E-I$ for all CA countries as seen in Table 7 imply that GDP increases bring export increases as seen in Table 8; they also bring more increases for imports in most CAC. Thus, negative impacts in total can be seen in Table 7. This may be slightly less for TUR's case as the coefficients estimates are not significant. Positive impacts can be seen from the fact that $G D P$ increase could bring more active economic activities to increase exports. Especially, we find that $G D P$ increases could bring much higher increase for trade activities as denoted by $E+I$ in Table 9 .

Generally, in most of the regression results we find that energy production $(E P R)$ has significantly positive impacts on all trade factors, among them in particular large impacts on export capability $(E)$ and trade volume $(E+I)$. Regarding the impact on $E-I$ and $E$, we see that only KAZ and TUR show significantly positive impacts. This results from the fact that KAZ produces a large amount of oil and then exports it, while TUR depends upon natural gas production largely. On the other hand, in both KYR and TAJ, EPR has a rather negative impact on trade activities as these countries do not have fossil energy resources such as oil and natural gas, depending rather on renewable energy resources such as hydro power. $F D I$ has significantly positive impacts in UZB and TUR, but its impact is not so significant in the other countries. This might come from the recent trend where these two countries are trying to attract substantial FDI from China, e.g. TUR's case of building a natural gas pipeline connecting with China.

Regarding the impacts due to oil and natural gas price changes denoted by $O L P$ and $N G P$, respectively, on trade activities we find that in countries beside TUR, $O L P$ increases have rather negative impacts on the trade balance $E-I$, while only TUR shows a significantly positive impact. On the other hand, NGP increases have rather positive impacts in all countries except TUR, which shows a negative impact. This might result from the fact that KAZ and UZB depend upon oil production and oil exports, and thus oil price increases have a negative impact on the trade balance as two countries have to import expensive energy resources, facing the demand decrease for the oil due to the higher price in the international market. TUR depends on mostly natural gas rather than oil, so $O L P$ increases bring higher trade revenue from higher natural gas export income. Interestingly, $N G P$ increases have significantly negative impacts on all trade activities for the natural gas depending country TUR. This may be because $N G P$ increases may bring higher import costs for consumer countries under the growing demand for the natural gas in recent years, resulting in a shift to fewer energy trade activities by shifting to renewable energy resources.

In group II countries KYR and TAJ, $O L P$ increases have rather negative impacts on the trade balance $E-I$ as they might have to import more expensive energy resources, and thus the impacts on trade activities such as $E$ and $E+I$ can be rather positive. $N G P$ increases have significantly negative impacts on trade activities $E$ and $E+I$ for TUR, KYR and TAJ as these countries need to depend upon some other energy resources besides oil and natural gas, e.g. renewable 
energy resources such as solar and wind power.

\section{Future Strategic Planning for the Energy and Trade Policy in the CAC}

\subsection{Energy and Trade Policy in the CAC}

Economies in the CAC demonstrate considerable divergence in their strategies, policies and goals despite having similar historical backgrounds. Their economic challenges and commonalties such as super-presidential political system also show rampant corruption, geographic obstacles to trade, reluctance to engage in serious regional cooperation, and so on. The transition period from a centrally planned economy to a market economy has prompted each of the CAC to identify its own strengths and weaknesses in the global market, and to build its action plan for economic growth. The central question addressed in this section is to what extent these CAC use their energy resources efficiently in their economic development, and what strategies would be most effective to achieve sustainable growth instead of focusing only on short-term performance.

As noted earlier, group I countries have substantial reserves of fossil energy resources such as oil, natural gas and coal. This fact has enabled KAZ, UZB and TUR to relatively easily overcome the transition hardships after the dissolution of the Soviet Union in contrast to group II countries KYR and TAJ, which experienced turmoil, unrest and revolts at different times, mostly because of their weak economies, extensive corruption and lack of resources. The abundant hydrocarbon resources in KAZ and TUR gave them outstanding opportunities to attract a great amount of foreign investment in their energy sectors and to increase oil, natural gas and coal production for exporting to Russia, China, Europe and the Middle East. Through this opportunity to obtain hard currency, they could achieve trade surpluses and strengthen their economies. In sharp contrast with the group I countries, the group II countries lack hydrocarbon resources. Thus, they needed to import oil, gas and coal from KAZ, UZB and TUR. These shortfalls were exacerbated by the civil war in TAJ's initial years of independence (1991-1997) and by repeated violent uprisings in KYR in response to injustice and unfairness in politics, and high commodity, utility, electricity and natural gas prices. As a consequence, the economies of these countries became weaker and more vulnerable to risk even though the hydro energy potential of both KYR and TAJ is large enough to generate and supply the whole CAC region with electricity, and in fact enough even to supply to other neighboring countries such as Pakistan, Afghanistan, Iran and India.

Gill et al. [50] claim that since the mid-1990s, Eurasia has benefited from its natural resource endowment, and all the countries in Eurasia have seen rise of incomes and the improvement of living standards. Indeed, during the period from 1998 to 2015 GDP increased on a large scale in all five CAC: tenfold in KAZ; fourteen fold in TUR; and more than four fold in UZB, KYR and TAJ. Their GDP per capita also significantly increased with a sizable decrease in the 
poverty rate. During the period from 2001 to 2015 the poverty rate was reduced by more than a half in all the nations of the region, with a colossal reduction in KAZ, where it diminished from $46.7 \%$ to $2.7 \%$. The available data from World Bank as shown in Figure 11 indicates that the share of rent from natural resources has increased sharply in both groups I and II countries, starting in 1998, with a marked spike in resource rich countries. TUR's share of rent from natural resources reached $80.9 \%$ of its GDP in 2001 and dropped to $18.9 \%$ in 2015 , whereas KAZ's and UZB's share reached $24.5 \%$ and $20.2 \%$, respectively, maintaining the same level over the last 15 years. In general, developing countries plan to achieve income growth and poverty reduction. The main ingredient in the recipe of such advancement is to increase productivity and create jobs, which require substantial amounts of capital investment.

According to the World Bank research (2014) the 10 year period 2000-2010 as shown in Table 10 exhibited positive changes in both productivity and employment growth in all five economies. TUR, TAJ and KAZ had the highest productivity growth rates, while KAZ, UZB and TUR showed the highest employment growth rates. These positive changes in employment and productivity growth rates indicate notable and meaningful improvements in the efficiency in the use of energy resource rents in the CAC.

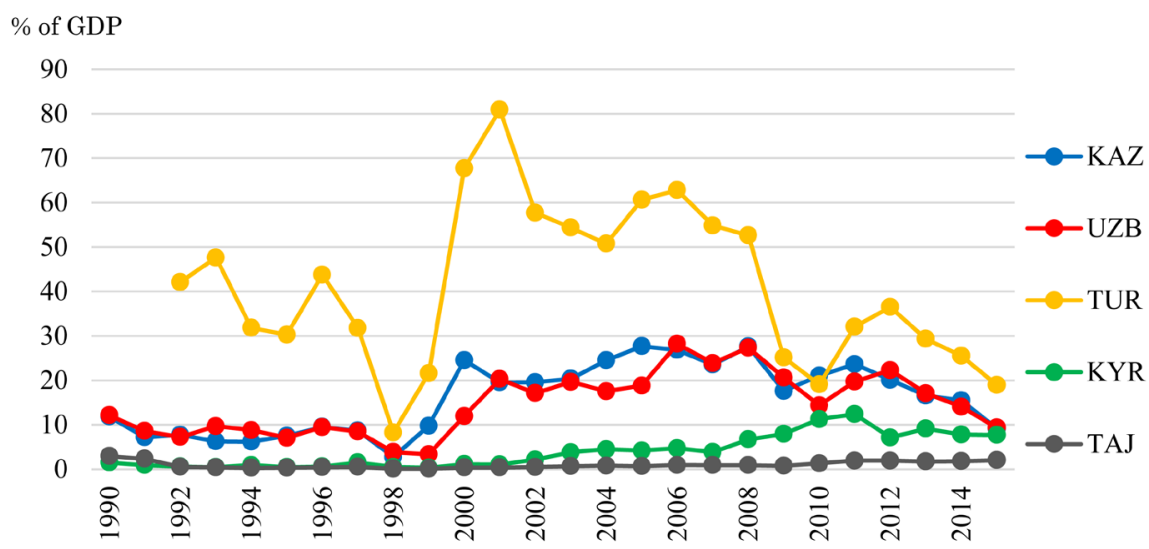

Figure 11. Total natural resources rents in the CA during 1990-2014. Data source: The World Bank: Diversified development. Making the most of natural resources in Eurasia, 2014.

Table 10. Annual average changes in employment, labor productivity, and volatility (2000-2010).

\begin{tabular}{cccc}
\hline Country & Employment growth & Productivity growth & Volatility of output \\
\hline KAZ & 2.2 & 5.9 & 3.3 \\
UZB & 2.9 & 3.6 & 1.1 \\
TUR & 2.2 & 10.9 & 4.8 \\
KYR & 1.9 & 2.1 & 3.3 \\
TAJ & 1.8 & 6.2 & 8.3 \\
\hline
\end{tabular}

Source: The World Bank: Diversified development. Making the most of natural resources in Eurasia. 2014. 
However, Table 10 shows that the volatility rate of output is particularly high in all countries of the region, except UZB, which could to some extent diversify its economy making it less specialized. The economies of TAJ and TUR are prone to high volatility due to their overdependence on a single export commodity, natural gas for TUR and aluminum for TAJ, and to fluctuations in the world prices of these commodities. High volatility rates have a negative impact on the steady economic growth of any country, and in the case of the commodity driven economies of the CAC, this makes their economies even more vulnerable in cases of global financial crises. The magnitude of the high volatility has been felt clearly in the two most recent world crises, which were followed by sharp declines in commodity prices resulting in the contraction of the sizes of the economies and incomes. The persistent declining trend of commodity prices and the demand for major export goods since 2011 have had even more damaging effects on the economies of the CAC. Thus, it is important that we consider what strategies would be the most appropriate to achieve sustainable growth while minimizing harmful effects from external risks such as global crises and commodity price fluctuations.

Myant \& Drahokoupil [51] examine the international integration and the structure of exports in the CAC. They identify shifts in the commodity composition of exports since the CAC's independence both in terms of the share of the major commodity groupings and in the quality of goods. They also address the differences in the CAC's trade performance. Diversification of the economy including exports is generally considered as the main solution to the problems. The CAC, in particular, see the gradual exit of their countries from the overdependence on major export commodities as indispensable to achieve their long-term goals, and thus place diversification of the economy at the top of their long term agenda. The largest exporter of energy resources in the CAC is KAZ with $62.1 \%$ of the total regional energy export. TUR is the second biggest exporter in the region with $30.0 \%$, while UZB's share is only $7.9 \%$. The share of energy in the structure of export commodities of KAZ and TUR constitute more than $80 \%$ of their total exports, therefore, their economies are critically dependent on the volume of their energy exports. In UZB, this share, compared to its hydrocarbon resources rich neighbors, is not as high, but it is still very significant (30\%). UZB's economy is more diverse than that of the other CAC, due to its larger population and broader initial industrial base. Auty 2007 also discusses the revenue curse issue emphasizing that reinforcing the rationale for the sound management of natural resources by providing an index of policy sustainability in the form of the net saving rate is important.

\subsection{Future Strategies for the Energy and Trade Policy}

The changes that have occurred in world politics and foreign policies over the last decade have significantly changed the trajectory of the trade structure in the CAC. The CAC expanded their oil and gas pipeline routes enabling them to export directly to growing and potential markets, which had significant impacts on 
the economic growth in these countries. The net growth in oil demand comes entirely from non-OECD countries: for each barrel of oil eliminated from the demand in OECD countries, two additional barrels of oil are consumed in the developing world. India and Nigeria are the countries with the highest rates of oil demand growth. China will become the largest oil-consuming country in the early 2030s.

As the past data for the CAC illustrate that all five countries' economies in the region have experienced continuous growth with large variations in degree, we assume that this growth will continue with a different pace for each country. We take into account the previous trend of the growth of the variables: $G D P, E P R$, Net FDI, OLP and NGP, for the period of 15 years (2000-2015); We also use the forecast of international organizations: the WB, IMF, IEA, OECD [52], International Futures (IFs) forecasting system (IFsFS) and the Pardee Center for International Futures at the University of Denver. Using IFsFS's forecast of $G D P$ growth for 2030 in the CAC we calculate the predicted volume of EPR in the region employing coefficients of our first regression model: given in (3) in Section 2.

In Table 11 we show our assumptions on the future annual growth rates in percentages for $G D P, E P R$, Net FDI, OLP and NGP, respectively, in the CAC. In Table 11 the data under column "I" represents the average annual growth rates of GDP, EPR, Net FDI, OLP and NGP in the CAC, which are used as reference data for predicting the future growth in 2030. Under column "II" we use the forecasted data from international organizations: IEA, International Futures (IFs) forecasting system (IFsFS) and the Pardee Center for International Futures at the University of Denver.

The average annual growth rate of the oil price, $O L P$, in 2000-2014 was 8.6\% reflecting the oil demand and OPEC's strategy. According to the IEA's World Energy Outlook [53] the price of oil in 2030 is predicted to be 125 USD, which is equal to an estimated average annual growth of $O L P$ of $1.5 \%$ compared with the 2014 price. We use the IEA's forecasted $O L P$ as we can anticipate both the growth

Table 11. Assumptions on the growth rates for GDP, Net FDI, OLP and NGP.

\begin{tabular}{ccccccccccc}
\hline \multirow{2}{*}{ Countries } & \multicolumn{2}{c}{$G D P$} & \multicolumn{2}{c}{$E P R$} & \multicolumn{2}{c}{$N e t F D I$} & \multicolumn{2}{c}{ OLP } & \multicolumn{2}{c}{$N G P$} \\
\cline { 2 - 11 } & I & II & I & II & I & II & I & II & I & II \\
\hline KAZ & 6.57 & 3.9 & 5.1 & 1.7 & 3.6 & 3.6 & 8.6 & 1.5 & 1.9 & 0.9 \\
UZB & 6.88 & 6.2 & 0.1 & -0.3 & 4.0 & 4.0 & 8.6 & 1.5 & 1.9 & 0.9 \\
TUR & 8.08 & 6.5 & 3.6 & 9.3 & 10.0 & 10.0 & 8.6 & 1.5 & 1.9 & 0.9 \\
KYR & 4.06 & 4.6 & 2.3 & 2.0 & 8.0 & 8.0 & 8.6 & 1.5 & 1.9 & 0.9 \\
TAJ & 7.16 & 5.9 & 2.3 & 4.9 & 5.0 & 5.0 & 8.6 & 1.5 & 1.9 & 0.9 \\
\hline
\end{tabular}

I: Average annual growth rates of $G D P, N e t F D I, O L P$ and $N G P$ in period 2000-2015, II: Forecasted annual growth rate of GDP, Net FDI, OLP and NGP in period 2015-2030. GDP and FDI in billion USD and EPR in Mtoe). Source: World Development Indicators, The World Bank, World Energy Outlook 2014, IEA, and International Futures (IFs) forecasting system (IFsFS), http://pardee.du.edu/. 
of the renewables share in world energy consumption and the development of shale oil in US and Canada and other main oil consumer countries. The former will be attained by technology development, while the latter will balance the growth of the oil price. For the $N G P$ forecast, we look back to the past trend of growth in $N G P$ in $2000-2014$, which exhibits $1.9 \%$ average annual growth rate, IEA forecasts moderate growth until 2030 with a $0.9 \%$ average annual growth rate. Due to the steady growth of the renewable share in the energy mix and the development of shale oil and shale gas in recent years, the demand for natural gas may not be as strong as in previous years. However, because of governments' policies and commitments on lowering $\mathrm{CO}_{2}$ and thus increased demand for cleaner energy resources, global demand for natural gas is predicted to increase in the future. Taking into account these factors, we based our forecast for NGP on IEA's forecast for 2030.

We use the estimated coefficients from the regression results for period II (2009-2014). In order to forecast the future impact of the CAC's EPR on their trade, we integrate our $E P R$ data for 2030 together with the predicted data for GDP, Net FDI, OLP and NGP into our regression model, shown in (2) in Section 3. Table 12 shows the future growth in 2030 in comparison with the data for 2014.

We are interested in measuring the size of the impact of the five variables described above on three factors, i.e., the trade balance $E-I$, export capability $E$, and total volume of trade $E+I$ in the CAC. We show numerical results and their analysis for the forecast for the future target year 2030 for each of $E-I, E$ and $E$ $+I$ in Table 13. KAZ's GDP growth rate for the past period is higher than the predicted for 2030 due to high oil price growth during the period from 2000 to 2014 (8.6\% annual growth), compared to the predicted $1.5 \%$ annual growth to 2030. Still, we can conclude from the model analysis that GDP growth in KAZ has a positive impact on $E P R$. At the same time, from our regression results on trade indictors we can see that $E P R$ has a large impact on its trade. Trade balance $E-I$ is forecast to improve by more than twice by 2030 , while export capability $E$ and total volume of trade $E+I$ are predicted to grow significantly. Since $E P R$ is

Table 12. Forecasting for 2030 in comparison with the data for 2014.

\begin{tabular}{ccccccccccc}
\hline & \multicolumn{2}{c}{$G D P$} & \multicolumn{2}{c}{$E P R$} & \multicolumn{2}{c}{ Net FDI } & \multicolumn{2}{c}{ OLP } & \multicolumn{2}{c}{ NGP } \\
\cline { 2 - 10 } & 2014 & 2030 & 2014 & 2030 & 2014 & 2030 & 2014 & 2030 & 2014 & 2030 \\
\hline KAZ & 183.0 & 338.3 & 166,2 & 218,1 & 7.5 & 12.1 & 98.9 & 125 & 5.4 & 6.3 \\
UZB & 53.8 & 139.7 & 55,8 & 53,5 & 0.6 & 5.6 & 98.9 & 125 & 5.4 & 6.3 \\
TUR & 34.9 & 95.8 & 77,9 & 323,6 & 4.1 & 9.6 & 98.9 & 125 & 5.4 & 6.3 \\
KYR & 5.8 & 11.9 & 1,9 & 2,6 & 0.3 & 1.0 & 98.9 & 125 & 5.4 & 6.3 \\
TAJ & 7.4 & 18.5 & 1,7 & 3,8 & 0.3 & 0.9 & 98.9 & 125 & 5.4 & 6.3 \\
\hline
\end{tabular}

Units: GDP and Net FDI in billions USD, EPR in Mtoe, $O L P$ and NGP in USD. Source: World Development Indicators, The World Bank, World Energy Outlook 2014, IEA, and International Futures (IFs) forecasting system (IFsFS), http://pardee.du.edu/. 
Table 13. Numerical Results for $E-I, E$, and $E+I$ for 2014 and 2030.

\begin{tabular}{|c|c|c|c|}
\hline & & 2014 & 2030 (Estimates) \\
\hline \multirow{3}{*}{ KAZ } & $E-I$ & 1.12 & 2.51 \\
\hline & $E$ & 67.72 & 83.60 \\
\hline & $E+I$ & 124.29 & 164.69 \\
\hline \multirow{3}{*}{ UZB } & $E-I$ & -25.26 & 2.23 \\
\hline & $E$ & 14.55 & 33.80 \\
\hline & $E+I$ & 31.63 & 65.37 \\
\hline \multirow{3}{*}{ TUR $^{*}$} & $E-I$ & 10.15 & 20.98 \\
\hline & $E$ & 25.71 & 69.54 \\
\hline & $E+I$ & 41.37 & 118.09 \\
\hline \multirow{3}{*}{ KYR } & $E-I$ & -3.75 & -5.57 \\
\hline & $E$ & 2.79 & 4.38 \\
\hline & $E+I$ & 9.34 & 14.34 \\
\hline \multirow{3}{*}{ TAJ } & $E-I$ & -4.18 & -7.49 \\
\hline & $E$ & 1.63 & 2.09 \\
\hline & $E+I$ & 9.34 & 14.34 \\
\hline
\end{tabular}

(Units: in billions of USD). *TUR's data for $E-I, E$, and $E+I$ are for 2012 .

strongly correlated with $G D P$ growth and healthy trade even in 2030 we can recommend KAZ to continue focusing on $E P R$.

In UZB's case, our regression results show that the $E P R$ impact on foreign trade is statistically insignificant, which implies that the diversification of the UZB economy may work effectively; thus the diversification tightens reserve constraints of the fossil fuels for UZB. Although our forecast for 2030 foreign trade shows that there will be no trade deficit, we can highly recommend the UZB government to utilize its huge potential to produce renewable energies which can further strengthen the foreign trade indicators. For TUR, the GDP growth was highly correlated with $E P R$ in both periods, however, period II demonstrated a stronger impact of $G D P$ growth on $E P R$ growth. This is possibly due to the building of new pipeline routes to China followed by large volume gas exports and massive Chinese investment into the energy sector of TUR. Trade balance $E-I$, export capability $E$ and total volume of trade $E+I$ in TUR are expected to grow by more than twice by 2030, which demonstrates the highest positive impact of $E P R$ on trade indicators among the CAC.

KYR's $G D P$ growth turned to have a positive correlation with $E P R$ in period II. KYR's $E P R$ has statistically significant negative correlation with $E$ and $E+I$, perhaps because KYR depends highly on energy imports. In our forecast of 2030 foreign trade figures, the trade balance is expected to be negative, which highlights the importance of investing in domestic EPR. KYR has vast potential to develop hydro energy generation with further exporting opportunities. It is also 
rich in coal reserves, and the development of the extraction of coal can free the country from fossil fuel import dependency. In TAJ, GDP growth has a positive correlation with $E P R$ in both periods. This correlation is weak in the period II mainly due to possibly lower investment and lower growth in EPR. TAJ's EPR has a statistically significant negative correlation with $E+I$, perhaps because of TAJ's high dependence on energy imports similar to the KYR case. TAJ also imports its oil, gas and coal resources from hydrocarbon rich neighbors. In our forecast of 2030, the trade balance of TAJ is also expected to be negative, while export capability $E$ and total volume of trade $E+I$ in TAJ are expected to grow slightly by 2030 . TAJ has significant volume of coal reserves, however, the infrastructure to extract coal is underdeveloped and requires substantial investment.

\section{Summary and Conclusion with Policy Recommendations}

The main objective of this study has been to examine the impact of energy production on economic growth and trade in the CAC, and to identify future energy strategic policies focusing upon the trade of energy resources. In order to investigate the relationship between energy production and economic growth we have used a mathematical model explaining the correlation of $E P R$ and $G D P$ for the two periods of "before" and "after" the Lehman shock in 2008, i.e., periods I: 1998-2009 and II: 2009-2014. To investigate the impact of energy production $(E P R)$ on trade, we apply another mathematical model using data on $G D P, E P R$, $F D I, O L P$ and $N G P$ as independent variables and trade balance $(E-I)$, export potential $(E)$, trade $(E+I)$ data as the main dependent variables. The relationship between $E P R$ and $G D P$ has been proved positive for both periods for most CAC. Through our regression results we have found that energy production $(E P R)$ has significant positive impacts on all trade factors, among them in particular large impacts on export capability $(E)$ and trade volume $(E+I)$.

In KAZ energy production grew almost proportionally to its $G D P$ growth, reflecting its massive production and export growth of oil with favorable price increases in the international oil market. Model estimates for UZB indicate a statistically significant positive relationship between $G D P$ and $E P R$ in period I, but a negative relationship for period II. This implies the lower dependency of the UZB economy on energy production and export. While this to a certain degree testifies to the more diversified status of UZB economy, it actually has a negative influence on its economy. Therefore UZB should take vigorous measures to make the best use of its hydrocarbon reserves and the potential of its renewable sources by creating an attractive environment for foreign capital inflow into its energy sector. Estimates for TUR's $G D P$ and $E P R$ demonstrate the higher elasticity for its period II on the ground that TUR started exporting its natural gas to China through pipeline. KYR's case demonstrated a statistically significant and positive relationship between $G D P$ and $E P R$ in period II, which is the result of the significant growth in coal production in the country after 2008. The sizeable increase of coal production in the country boosted its share in KYR's energy mix 
from $9.1 \%$ in 2006 to $34.4 \%$ in 2014 . The regression computation indicated a positive and significant result for TAJ in both periods, which has vast potential regarding hydro power generation. The historical data of TAJ's GDP and energy production demonstrate the balanced and interdependent growth in this country.

$G D P$ has different impacts on $E-I, E$, and $E+I$. It has a slightly negative effect on $E-I$, while it has mostly significant and positive impacts on both $E$ and $E+I$. GDP increases lead to export increases and sometimes more slightly increases for imports in most CAC. EPR has significantly positive impacts on all trade factors, among them in particular large impacts on $E$ and $E+I$. It has significant positive impact on $E-I$ and the energy potential of two large energy exporting countries KAZ and TUR. Hydrocarbon resource poor countries KYR's and TAJ's EPR have a rather negative impact on the trade activities since both countries depend on the import of fossil energy resources such as oil and natural gas. FDI causes significantly positive impacts on the trade balance of UZB and TUR, reflecting large FDI from China.

$O L P$ increases have a rather negative impact on the trade balance, while only TUR shows a significantly positive impact. On the other hand, NGP increases have rather positive impacts in all countries, except TUR. This might result from the fact that KAZ greatly depends upon oil production and exports, and thus oil price increases have a negative impact on the trade balance as it decreases the demand for oil, while TUR depends on mostly natural gas rather than oil. Therefore oil price increase brings higher trade revenue from higher natural gas export income. Interestingly, natural gas price increase brings significantly negative impacts on all trade activities for the natural gas depending country TUR.

Our findings can be summarized as follows: EPR growth has statistically significant positive impacts on $G D P$ growth in fossil-fuel rich group I countries, and in hydro energy rich TAJ. Also for group I countries, EPR has significantly positive impact on all trade factors, among them in particular a large impact on $E$ and $E+I$, while group II countries' $E P R$ has a rather negative impact on trade activities since these countries depend on the import of fossil energy resources such as oil and natural gas. GDP growth has a positive impact on $E$ and $E+I$ in the CAC, although it has a slightly negative impact on the trade balance $E-I$. $F D I$ has a significant influence on the balance of trade $E-I$ in the cases of UZB and TUR. $O L P$ and $N G P$ increases have positive impact on the trade balance $E-$ $I$ of TUR and KAZ, respectively.

Since $E P R$ is highly correlated with GDP growth and healthy trade even in the 2030 forecast figures, we can recommend that group I countries continue to focus on energy production by investing further in the exploration works of new hydrocarbon reserves and upgrading infrastructure on both the demand and supply side through energy saving policies and the development of renewables, where all CAC have huge potentials. In group II countries GDP growth is positively correlated with $E P R$ for both countries in period II. Moreover, KYR's EPR has a statistically significant negative correlation with $E$ and $E+I$, while TAJ's 
$E P R$ has a statistically significant negative correlation with only $E+I$. Since our forecast for 2030 demonstrates negative foreign trade figures for both KYR and TAJ, it is important for them to invest in domestic $E P R$, especially in coal and renewables.

\section{Conflicts of Interest}

The authors declare no conflicts of interest regarding the publication of this paper.

\section{References}

[1] Spechler, M. (2000) Regional Cooperation in Central Asia: Promises and More Promises. The Fletcher Journal of Development Studies, 16, 1-11.

[2] Antonakakisa, N., Cunadoc, J., Filisd, G. and Perez de Gracia, F. (2017) Oil Dependence, Quality of Political Institutions and Economic Growth: A Panel VAR Approach. Resources Policy, 53, 147-163. https://doi.org/10.1016/j.resourpol.2017.06.005

[3] Auty, R. (1998) Mineral Wealth and the Economic Transition: Kazakhstan. Resources Policy, 24, 241-249. https://doi.org/10.1016/S0301-4207(98)00036-1

[4] Auty, R. (2001) Transition Reform in the Mineral-Rich Caspian Region Countries. Resources Policy, 27, 25-32. https://doi.org/10.1016/S0301-4207(01)00005-8

[5] Auty, R. (2001) The Political State and the Management of Mineral Rents in Capital Surplus Economies: Botswana and Saudi Arabia. Resources Policy, 27, 77-86. https://doi.org/10.1016/S0301-4207(01)00008-3

[6] Auty, R. (2001) The Political Economy of Resource-Driven Growth. European Economic Review, 45, 839-846. https://doi.org/10.1016/S0014-2921(01)00126-X

[7] Auty, R. (2003) Natural Resources and "Gradual” Reform in Uzbekistan and Turkmenistan. Natural Resources Forum, 27, 255-266. https://doi.org/10.1111/j.0165-0203.2003.00060.x

[8] Auty, R. (2007) Natural Resources, Capital Accumulation and the Resource Curse. Ecological Economics, 61, 627-634. https://doi.org/10.1016/j.ecolecon.2006.09.006

[9] Barry, M. (2009) Dutch Disease in Uzbekistan? A Computable General Equilibrium Model of Effects of Foreign Investment into Uzbekistan's Gas Sector. Caucasian Review of International Affairs, 3.

[10] Franke, A., Gawrich, A. and Alakbarov, G. (2009) Kazakhstan and Azerbaijan as Post-Soviet Rentier States: Resource Incomes and Autocracy as a Double "Curse" in Post-Soviet Regimes. Europe-Asia Studies, 61, 109-140. https://doi.org/10.1080/09668130802532977

[11] Sachs, J. and Warner, A. (2001) The Curse of Natural Resources. European Economic Review, 45, 827-838. https://doi.org/10.1016/S0014-2921(01)00125-8

[12] Agzamov A., Anvarov A. and Shakirov, K. (1995) Economic Reform and Investment Priorities in the Republic of Uzbekistan. Comparative Economic Studies, 37, 27-38. https://doi.org/10.1057/ces.1995.19

[13] Pomfret, R. (2010) Constructing Market-Based Economies in Central Asia: A Natural Experiment? The European Journal of Comparative Economics, 7, 449-467.

[14] Pomfret, R. (2012) The Economic Future of Central Asia. Brown Journal of World Affairs, xix.

[15] Ahmed, M. and Azam, M. (2016) Causal Nexus between Energy Consumption and 
Economic Growth for High, Middle and Low Income Countries Using Frequency Domain Analysis. Renewable and Sustainable Energy Reviews, 60, 653-678. https://doi.org/10.1016/j.rser.2015.12.174

[16] Apergis, N. and Payne, J. (2009) Energy Consumption and Economic Growth: Evidence from the Commonwealth of Independent States. Energy Economics, 31, 641-647. https://doi.org/10.1016/j.eneco.2009.01.011

[17] Apergis, N. and Payne, J. (2010) Renewable Energy Consumption and Growth in Eurasia. Energy Economics, 32, 1392-1397. https://doi.org/10.1016/j.eneco.2010.06.001

[18] Apergis, N. and Payne, J. (2010) The Emissions, Energy Consumption, and Growth Nexus: Evidence from the Commonwealth of Independent States. Energy Policy, 38, 650-655. https://doi.org/10.1016/j.enpol.2009.08.029

[19] Asafu-Adjaye, J. (2000) The Relationship between Energy Consumption, Energy Prices and Economic Growth: Time Series Evidence from Asian Developing Countries. Energy Economics, 22, 615-625. https://doi.org/10.1016/S0140-9883(00)00050-5

[20] Bildirici, M. and Kayıkçı, F. (2012) Economic Growth and Electricity Consumption in Former Soviet Republics. Energy Economics, 34, 747-753. https://doi.org/10.1016/j.eneco.2012.02.010

[21] Bildirici, M. and Kayıkçı, F. (2013) Effect of Oil Production on Economic Growth in Eurasian Countries: Panel ARDL Approach. Energy, 49, 156-161. https://doi.org/10.1016/j.energy.2012.10.047

[22] Bildirici, M. and Kayıkçı, F. (2016) Effects of Energy Consumption on Growth in Eurasian Countries. Procedia Economics and Finance, 38, 271-279. https://doi.org/10.1016/S2212-5671(16)30199-X

[23] Chiou-Wei, S., Chen, C. and Zhu, Z. (2008) Economic Growth and Energy Consumption Revisited-Evidence from Linear and Nonlinear Granger Causality. Energy Economics, 30, 3063-3076. https://doi.org/10.1016/j.eneco.2008.02.002

[24] Chontanawat, J., Hunt, L. and Pierse, R. (2008) Does Energy Consumption Cause Economic Growth? Evidence from a Systematic Study of over 100 Countries. Journal of Policy Modeling, 30, 209-220. https://doi.org/10.1016/j.jpolmod.2006.10.003

[25] Chuanhe, X., Degang, Y., Jinwei, H. and Yannan, Z. (2015) The Relationship between Energy Consumption and Economic Growth and the Development Strategy of a Low-Carbon Economy in Kazakhstan. Journal of Arid Land, 7, 706-715. https://doi.org/10.1007/s40333-015-0132-y

[26] Dogan, E. (2014) Energy Consumption and Economic Growth: Evidence from Low-Income Countries in Sub-Saharan Africa. International Journal of Energy Economics and Policy, 4, 154-162.

[27] Ebohon, O. (1996) Energy, Economic Growth and Causality in Developing Countries. Energy Policy, 24, 447-453. https://doi.org/10.1016/0301-4215(96)00027-4

[28] Eggoh, J., Bangake, C. and Rault, C. (2011) Energy Consumption and Economic Growth Revisited in African Countries. Energy Policy, 39, 7408-7421. https://doi.org/10.1016/j.enpol.2011.09.007

[29] Lee, C. (2005) Energy Consumption and GDP in Developing Countries: A Cointegrated Panel Analysis. Energy Economics, 27, 415-427. https://doi.org/10.1016/j.eneco.2005.03.003

[30] Mudarissov, A. and Lee, Y. (2014) The Relationship between Energy Consumption and Economic Growth in Kazakhstan. Geosystem Engineering, 17, 63-68. 
https://doi.org/10.1080/12269328.2014.895083

[31] Ozturk, I., (2010) A Literature Survey on Energy-Growth Nexus. Energy Policy, 38, 340-349. https://doi.org/10.1016/j.enpol.2009.09.024

[32] Sentürka, C. and Satafa, C. (2015) The Determination of Panel Causality Analysis on the Relationship between Economic Growth and Primary Energy Resources Consumption of Turkey and Central Asian Turkish Republics. Procedia-Social and Behavioral Sciences, 195, 393-402. https://doi.org/10.1016/j.sbspro.2015.06.342

[33] Sharma, S. (2010) The Relationship between Energy and Economic Growth: Empirical Evidence from 66 Countries. Applied Energy, 87, 3565-3574. https://doi.org/10.1016/j.apenergy.2010.06.015

[34] Soares, J., Kim, Y. and Heo, E. (2014) Analysis of Causality between Energy Consumption and Economic Growth in Indonesia. Geosystem Engineering, 17, 58-62. https://doi.org/10.1080/12269328.2014.889267

[35] Soytas, U. and Sari, R. (2003) Energy Consumption and GDP: Causality Relationship in G-7 Countries and Emerging Markets. Energy Economics, 25, 33-37. https://doi.org/10.1016/S0140-9883(02)00009-9

[36] Tsani, S. (2010) Energy Consumption and Economic Growth: A Causality Analysis for Greece. Energy Economics, 32, 582-590. https://doi.org/10.1016/j.eneco.2009.09.007

[37] Tugcu, C., Ozturk, I. and Aslan, A. (2012) Renewable and Non-Renewable Energy Consumption and Economic Growth Relationship Revisited: Evidence from G7 Countries. Energy Economics, 34, 1942-1950. https://doi.org/10.1016/j.eneco.2012.08.021

[38] Yuan, J., Kang, J., Zhao, C. and Hu, Z. (2008) Energy Consumption and Economic Growth: Evidence from China at Both Aggregated and Disaggregated Levels. Energy Economics, 30, 3077-3094. https://doi.org/10.1016/j.eneco.2008.03.007

[39] Yu, E. and Hwang, B. (1984) The Relationship between Energy and GNP: Further Results. Energy Economics, 6, 186-190. https://doi.org/10.1016/0140-9883(84)90015-X

[40] Lee, C. and Chang, C. (2008) Energy Consumption and Economic Growth in Asian Economies: A More Comprehensive Analysis Using Panel Data. Resource and Energy Economics, 30, 50-65. https://doi.org/10.1016/j.reseneeco.2007.03.003

[41] World Bank Data. http://data.worldbank.org/indicator

[42] Asian Development Bank (2010) Central Asian Countries Initiative for Land Management. Atlas of Natural Resources of Central Asia 2010.

https://www.adb.org/sites/default/files/publication/27508/central-asia-atlas.pdf

[43] Wada, I. (2017) Energy Production and Economic Growth in Saudi Arabia: Dynamic Causality. Energy Sources, Part B: Economics, Planning, and Policy, 12, 584-590. https://doi.org/10.1080/15567249.2016.1248872

[44] Ahmad, N. and Du, L. (2017) Effects of Energy Production and $\mathrm{CO}_{2}$ Emissions on Economic Growth in Iran: ARDL Approach. Energy, 123, 521-537. https://doi.org/10.1016/j.energy.2017.01.144

[45] Sambodo, M.T., Morohosi, T. and Oyama, T. (2017) Developing a Green Path Power Expansion Plan in Indonesia by Applying a Multiobjective Optimization Modeling Technique. Journal of Energy Engineering, 143, No. 3. https://doi.org/10.1061/(ASCE)EY.1943-7897.0000392

[46] Ozkan, F., Ozkan, O. and Kuyuk, H.S. (2012) Energy Production and Economic Growth: Empirical Evidence from Turkey. Applied Econometrics and International 
Development, 12, 79-88.

[47] Liu, Y. (2013) Energy Production and Regional Economic Growth in China: A More Comprehensive Analysis Using a Panel Model. Energies, 6, 1409-1420. https://doi.org/10.3390/en6031409

[48] Peach, J. and Starbuck, C.M. (2011) Oil and Gas Production and Economic Growth in New Mexico. Journal of Economic Issues, 45, 511-526. https://doi.org/10.2753/JEI0021-3624450228

[49] Reynolds, D. and Kolodziej, M. (2008) Former Soviet Union Oil Production and GDP Decline: Granger Causality and the Multi-Cycle Hubbert Curve. Energy Economics, 30, 271-289. https://doi.org/10.1016/j.eneco.2006.05.021

[50] Gill, I.S., Izvorski, I., Eeghen, W. and Rosa, D. (2014) Diversified Development: Making the Most of Natural Resources in Eurasia. World Bank, Washington DC. https://doi.org/10.1596/978-1-4648-0119-8

[51] Myant, M. and Drahokoupil, J. (2008) International Integration and the Structure of Exports in Central Asian Republics. Eurasian Geography and Economics, 49, 604-622. https://doi.org/10.2747/1539-7216.49.5.604

[52] Organization for Economic Co-Operation and Development \& International Energy Agency (2015) Eastern Europe, Caucasus and Central Asia: Energy Policies beyond IEA Countries.

https://www.iea.org/publications/freepublications/publication/IDR_EasternEurope Caucasus_2015.pdf

[53] International Energy Agency (2014) Statistics. http://www.iea.org/statistics/ 